Document downloaded from:

http://hdl.handle.net/10251/28793

This paper must be cited as:

Bermúdez, V.; Piqueras, P.; Garcia Afonso, O.; Serrano Cruz, JR. (2011). Assessment by means of gas dynamic modelling of a pre-turbo diesel particulate filter configuration in a turbocharged HSDI diesel engine under full-load transient operation. PROCEEDINGS OF THE INSTITUTION OF MECHANICAL ENGINEERS PART D-JOURNAL OF AU. 225(9):1134-1155. doi:10.1177/0954407011402278.

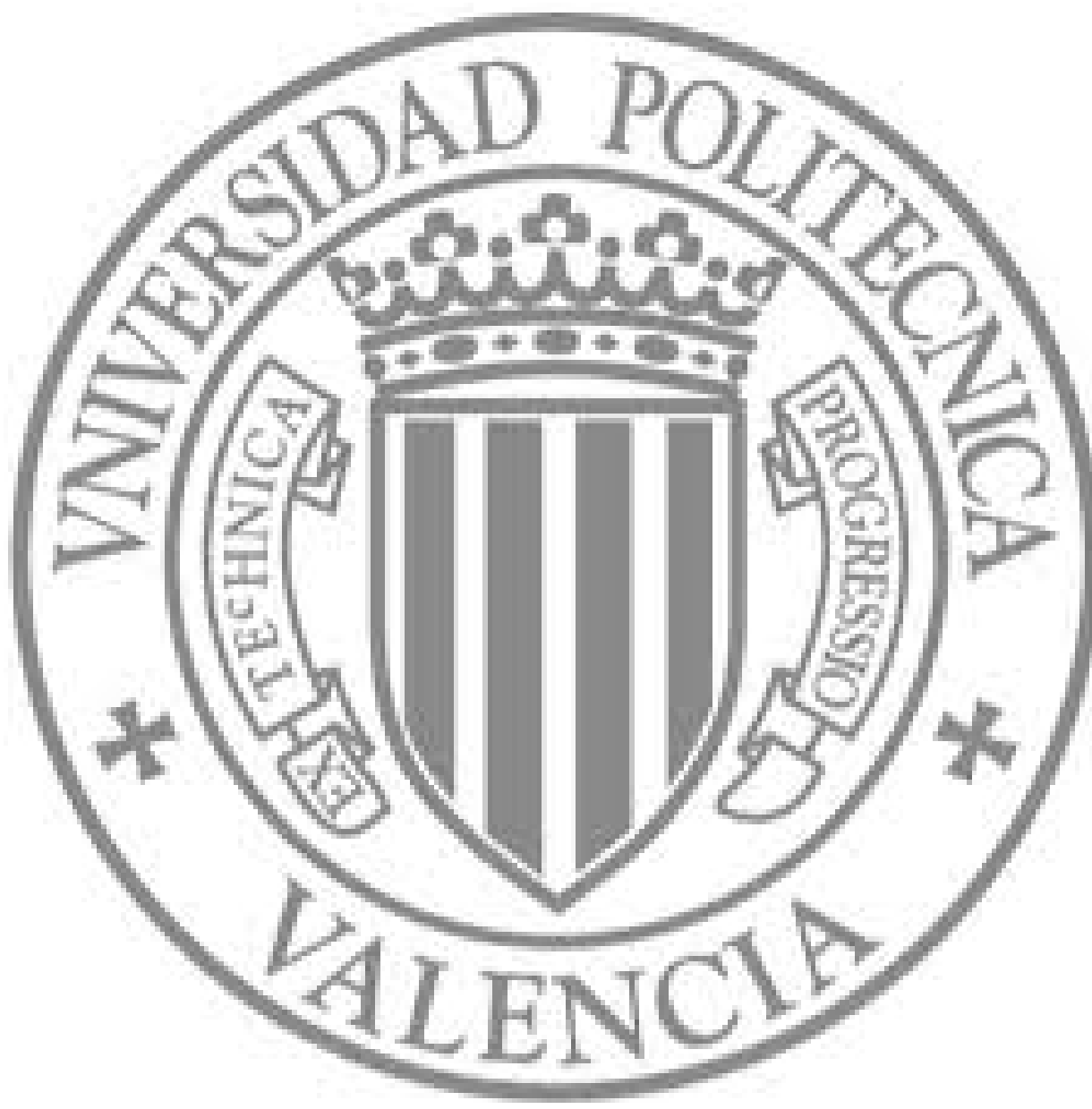

The final publication is available at

http://pid.sagepub.com/content/225/9/1134.full.pdf+html

Copyright

SAGE Publications 


\title{
Assessment by means of gas dynamic modelling of a pre-turbo diesel particulate filter configuration in a turbocharged HSDI diesel engine under full- load transient operation
}

\author{
V. Bermúdez, J.R. Serrano, P. Piqueras, O. García-Afonso \\ Universidad Politécnica de Valencia, CMT - Motores Térmicos
}

\begin{abstract}
Diesel particulate filters (DPF) are becoming a standard technology in diesel engines because of the need of compliance with oncoming regulations regarding soot emissions. Once a great degree of maturity in management of filtration and regeneration has been reached, the influence of the DPF placement on the engine performance emerges as a key issue needing to be properly addressed. The novelty of this work leads to the study of an unusual location of an aftertreatment device in the architecture of the turbocharged Diesel engine exhaust line. The problem of the pre-turbo DPF placement is tackled comparing the engine response under full-load transient operation versus the traditional DPF location downstream the turbine. The study has been performed on the basis of a gas dynamic simulation of the engine, which has been validated with experimental data obtained under steady state and transient conditions. The DPF response has been simulated with a model able to deal with the characteristic highly pulsating flow upstream of the turbine. Several levels of DPF soot loading has been considered to properly represent the most exigent conditions in terms of performance requirements. As a result, the main physical phenomena controlling the engine and DPF response and interaction have been identified. In concrete, to place the DPF upstream the turbine will lead to an number of important advantages due to the continuous regeneration mode at which DPF will operate, the lower pressure drop in the DPF and the thermal energy storage in the DPF very useful to mitigate 'turbocharger lag' during engines transient operation. These three effects have been evidenced with calculations performed with the validated model and the results have been properly analyzed and discussed through the paper.
\end{abstract}

Page 1 of 49 
Key words: transient operation, full-load transient test, diesel engine, diesel particulate filter, exhaust line architecture

\section{CONTACT INFORMATION}

Corresponding author: J.R. Serrano. Universidad Politécnica de Valencia, CMT - Motores Térmicos. Camino de Vera s/n, 46022 Valencia, Spain. Phone: +34 963879657 Fax: +34 963877659 e-mail: jrserran@ mot.upv.es

\section{Introduction}

Diesel engine development is included among the most notable improvements of internal combustion engines. Since its invention it has had numerous applications and a growing acceptance and nowadays it has become the most efficient propulsive system in the automotive sector, both for passenger cars and heavy duty applications.

Up to the current state of art, the diesel engine has undergone an intense evolutionary process, which has been especially important during last decades. It has gone from heavy loud diesel engines of low performance to diesel engines characterized by its reliability, low consumption, low operating costs and huge potential in their capabilities. To this new vision from the public, several technological advances have contributed, like for example turbocharging, injection systems or electronic control, but certainly also the impact of a high scientific and technological effort on the emissions reduction.

In this regard, the increasingly stringent anti-pollution regulations in Europe, which are currently set by Euro 5 and Euro 6 proposal, which entries into force in 2014 [1], have an important role. Proof of this is that the current emission limits of nitrogen oxides and soot particulates for diesel engines are leading OEMs to an extensive implantation of after-treatment systems [2].

Although the early developments carried out on the DPF systems date back several decades [3][4], implantation and marketing of these systems has so far been delayed until last decade. Reasons are found on the benefits with respect to soot emissions given by improvements related to the combustion process. Nevertheless, nowadays the combination of advances involving diesel engine combustion with parallel advances on soot filtration technology has led to improve the performance of the DPF and to reduce the implications on the engine response. Currently, there are available solutions for both passenger vehicles and heavy-duty transport, which are product of the high scientific research carried out in recent years on DPF systems as noted Konstandopoulos [5]. Page 2 of 49 
Most filters are made of ceramic substrates conforming honeycomb wall-flow monoliths [6] with high filtration efficiency and less penalty on fuel consumption due to the combination of active regeneration techniques and passive solutions [7]. In this regard, future developments are devoted to obtain long mechanical and chemical durability looking for an increase of the capacity for ash accumulation [8], multifunctional monolith reactors [9][10], advances in catalyst for porous ceramic materials [11], characterisation of soot for filtration efficiency and regeneration improvement [12][13] or novel multi-functional configurations of the exhaust line involving the DPF placement upstream of the turbine [14][15].

The complexity arising from the use of these solutions requires that the research works have to be directed by a right combination of experimental techniques and simulation tools based on computer fluid-dynamics calculation. The use of simulation tools helps to control costs and to optimize the integration of the aftertreatment system into the engine. These tools offer the possibility of reaching a high level of understanding about involved phenomena that are not always accessible by empirical way.

The modelling of DPF systems has been constrained to their traditional location downstream of the turbine, most frequently preceded by the oxidation catalyst, which shifts the balance between NO and $\mathrm{NO}_{2}$ to $\mathrm{NO}_{2}$ and contributes to favour the soot oxidation [16]. Accordingly, main models for the thermal-and fluid dynamic study of wall-flow DPF assumes the flow to be quasi-steady. This is the case of the Bisset's model [17] for wall-flow DPF, which deals with the problem of the regeneration based on the solution of the non-linear system of differential equations describing the conservation of mass, momentum and energy inside the channels of the monolith. This model is the basis of any subsequent proposal, either $1 \mathrm{D}$ or $2 \mathrm{D}$, because of the clarity and rigor to set out the main fluid dynamic aspects of a wall-flow DPF.

Despite of a multitude of DPF models, there is a lack of models able to deal with the essentially non-homentropic one-dimensional unsteady compressible flow typical from internal combustion engines. The DPF would be exposed to this kind of flow characteristics if it were placed upstream of the turbine. At this location, the DPF pressure drop is affected as shown in [18], which analyses the effect of the pre-turbo configuration although neglecting variations in the turbine operation and assuming the flow across the DPF to be quasi-steady. Unsteady compressible flow has been considered only by Cunningham [19] and Piscaglia [20]. However, Cunningham's model is 
restricted by the assumption of isothermal flow, whereas Piscaglia's model is integrated into a gas dynamic code that solves the fluid dynamics of the DPF by means of a multi-duct configuration, thus resulting in a complex solution with a high computational cost.

In this context, a wall-flow self-developed DPF model formulated for non-homentropic onedimensional unsteady compressible flow is applied in this study [21][22]. The model is integrated into OpenWAM ${ }^{\mathrm{TM}}$ [23][24][25], an open source gas dynamic software for internal combustion engine modelling developed at CMT-Motores Térmicos. The use of these simulation tools ensures a proper treatment of the flow properties independently of the DPF placement, which is modelled both downstream and upstream of the turbine. Additionally, the turbocharged engine performance can be rigorously assessed with a suitable simulation of the turbocharger system [26]. With regard to the DPF, also the increase of the thermal level, which may feed further analysis regarding selfongoing passive regeneration, can be evaluated. Such an increase means two positive effects on the fuel consumption: on the one hand, its minimization because of the lower level of soot loading and, on the other hand, the reduction of active regeneration events, which would lead also to lower fuel consumption.

The study of this paper highlights that the engine performance, as a function of the exhaust line architecture, is governed by the combined effects of the thermal inertia of the DPF substrate and the temperature and pressure drop taking place across it. The fact that the pressure pulse lamination (and the destruction of the associated kinetic energy in the DPF) leads to a constant-pressureturbocharging operation when the DPF is placed upstream the turbine has to be also included. The influence of these parameters is shown by means of the simulation of full-load transient operation conditions at constant engine speed [23][27]. Load transient calculation allows evaluating both the stable operation performance, when full-load conditions are reached, and obviously also the performance of the engine dynamics during the load transient phase.

\section{Engine modelling}

The analysis of the influence that the DPF placement has on the engine performance was carried out simulating full-load transient operation at constant engine speed with a gas dynamics software socalled OpenWAM. The simulations were performed on a turbocharged HSDI diesel engine for passenger car, whose main characteristics are shown in

Page 4 of 49 
Table 3.

\section{TABLE 1}

Previously to this study, the engine model was tuned up both under steady state and full-load transient operation conditions taking as reference experimental data obtained in an engine test bench. Tests were conducted with the standard architecture of the exhaust line, i.e. post-turbo DPF placement, as represented Figure 20, which shows the scheme of the engine in OpenWAM's interface.

\section{FIGURE 1}

The tune up of the engine model under steady state conditions consisted of modelling several partial load operating points. The comparison between experimental data and modelled results representing the engine operating conditions is shown in Figure 21. The maximum difference between the tests and the model in mean variables is limited to $\pm 3 \%$ for every of the operating points and magnitudes. Therefore, the model provided good accuracy but also consistency regarding the prediction of the different aspects describing the engine operation, as performance, turbocharger operation and flow properties.

FIGURE 2

The next step comprised the modelling of full-load transient tests at constant engine speed. In comparison with the simulation of steady state conditions, the gas dynamic modelling of full-load transient operation requires additional data related to engine control strategies. In this case, the Page 5 of 49 
control of the VGT, the boost control and the injection system was implemented into OpenWAM as user-functions defined by ECU data. The EGR control was not considered because of the fact that the tests were performed with the EGR valve closed, following full-load transient strategy of the ECU. Main control actuations for modelling are described in following items and sketched in Figure 22:

- The communication between OpenWAM's code and the control module is set every $20 \mathrm{~ms}$.

- The engine speed is kept constant during all the full-load transient simulation.

$\circ$ The fuel mass is calculated by applying the boost control and the torque limiter, which have as input data the air mass flow and the engine speed.

○ The VGT position remains constant during engine operation at zero-load conditions due to the fact that the air mass flow is controlled by the injected fuel mass and the EGR rate, which in this case is null because the EGR valve is closed. Therefore, the initial VGT position is known from experimental data. Once the full-load transient operation starts, the control module imposes a target intake pressure, which is function of the engine speed and the fuel mass at full-load conditions. The error between the demanded intake pressure and the actual intake pressure feeds a PID controller that acts on the VGT position. The stator and the rotor effective areas and the turbine efficiency can be calculated from turbine maps once known the VGT position [26].

\section{FIGURE 3}

Finally, it is important to note that the modelling of engines under transient operation has a critical task in the prediction of the combustion process. In this study a technique to interpolate the rate of heat release (RoHR) versus the crank angle value from an engine database was applied.

The engine database represents the transient operation range of the engine homogenously. It contains a set of RoHR defined by means of combined Wiebe's functions. The parameters defining the Wiebe's functions were obtained from a phenomenological parametrization of the RoHR [28], Page 6 of 49 
which was previously determined from the post-processing of the experimental in-cylinder pressure with a combustion diagnostic code [29].

Every RoHR in the database is associated to their respective average cycle variables, which are referred as interpolation parameters. The interpolation parameters define a n-dimensional space in which is possible to calculate the distance from the current operating conditions to every point composing the engine database. The interpolation technique, which is described in detail in [23], is based on a weighted linear interpolation between several RoHR. In this work it was adapted to take into account the necessity of distinguishing between, on the one hand, the interpolation of the combustion beginning and, on the other hand, the interpolation of the RoHR value as function of the crank angle.

The interpolation parameters defining the n-dimensional space to determine the RoHR value are the air mass, the EGR mass, the injected fuel mass, the engine speed and the charged air density. As regards the beginning of the combustion, the n-dimensional space is defined by the start of the fuel injection (SOI), the engine speed, the air to fuel ratio, the EGR mass and the charged air density. During the simulation of full-load transient operation every of these parameters is provided by OpenWAM, with the only exception of the SOI. It is given by ECU data implemented into the control module.

The ability for an accurate prediction of the non-dimensional heat release law (HRL) of the couple formed by the engine database and the interpolation model is shown in Figure 23 for different steady state conditions not used to built the interpolation database. Although slight differences appear mainly in the prediction of the combustion beginning, as most clearly shown in Figure 23(d), it is observed a good agreement between the experimental and the predicted HRL along the whole combustion process and in a wide engine operation range both regarding engine speed and load.

\section{FIGURE 4}

Two full-load transient tests were modelled in order to obtain a reliable setup of the engine model. These tests correspond to $1500 \mathrm{rpm}$ and $2500 \mathrm{rpm}$ engine speeds. 
The tests were carried out after the steady state conditions of the engine at full-load conditions were reached. It ensures the complete stabilization of the wall temperature previously to the beginning of the full-load transient test. Next, the engine was moved to zero-load conditions, where it remained until the turbocharger achieved a stable speed. At this moment the full-load transient operation began by throttling the engine from zero to $100 \%$ load at constant engine speed.

Figure 24 shows the comparison between the main of the measured magnitudes and the corresponding modelled results both for $1500 \mathrm{rpm}$ (dashed line) and $2500 \mathrm{rpm}$ (continuous line). The measurement and the post-processing of the experimental data were performed according to the guidelines given in [29]. The good agreement between experimental and modelled data for both engine speeds proves that the model is fully able to reproduce the dynamics of the engine response.

\section{FIGURE 5}

Figure 24(a) shows the accurate reproduction of the air mass flow that the model obtains. It ensures an accurate prediction of the injected fuel mass with the help of the boost control, as observed in Figure 24(b). The prediction of the air mass flow through the engine and the energy released during the combustion process is fed back with the modelling of the turbocharger response, which also shows close agreement with experimental data, as Figure 24(c), (d) and (e), which correspond to intake pressure, turbine inlet pressure and turbocharger speed respectively, confirm. Finally, Figure 24(f) plots the engine torque, which shows also good agreement between experimental data and modelling results, as expected from the accuracy in the prediction of the flow properties along the engine and in the simulation of the combustion process.

\section{DPF model}

The one-dimensional model for honeycomb wall-flow DPF includes the solution of the flow unsteadiness. This characteristic is essential for the description of the flow properties upstream of the turbine, where the DPF is proposed to be placed. The formulation of the model is described in the Appendix.

Page 8 of 49 
Figure 25 shows the representation of the DPF model in OpenWAM's interface. At this figure, the big rectangles represent $0 \mathrm{D}$ elements, which correspond to the inlet and outlet volumes of the DPF. The large cone angle of the inlet an outlet volumes does not permit a $1 \mathrm{D}$ modelling of these elements [30] and as solution is taken to solved them as OD elements by means of a filling and emptying model. The medium size squares, numbered from 1 to 6 , represent boundary conditions. The 1D elements, such as ducts and monolith channels, are represented by solid lines connecting the boundary conditions. The monolith channel 1 represents an inlet channel whereas the channel 2 is an outlet channel. The grey arrows indicate the existence of flow through the porous medium.

The solution of the monolith channels provides the pressure drop due to non-inertial mechanisms, i.e. flow through the porous medium and flow-wall friction. The remaining pressure drop contributions, which are inertial, are modelled by boundary conditions connecting 0D and 1D elements. By means of these boundaries, based on the Benson's proposal [31], the pressure drop at the inlet and outlet of every volume is calculated defining discharge coefficients, which relates the effective area of the junction between the 1D element and the volume with the geometrical area. According to the numbering shown in Figure 25:

- Boundary condition 1 accounts for the pressure drop due to the flow expansion at the inlet cone of the filter.

- Boundary condition 2 accounts for the pressure drop due to the local flow contraction when entering the inlet monolith channels.

- Boundary condition 5 accounts for the pressure drop due to the local flow expansion when exiting from the outlet monolith channels.

- Boundary condition 6 accounts for the pressure drop due to the flow contraction in the outlet cone of the filter.

The monolith description is completed with the inclusion of the boundary conditions 3 and 4 represented in Figure 25, which model the alternatively plugged ends at inlet and outlet channels.

FIGURE 6

Page 9 of 49 
This model was applied to the characterization of the DPF used in the parametric study carried out to analyze the influence of the DPF placement on the engine response. The geometrical specifications of the DPF are summarized in Table 4.

The DPF pressure drop was characterized under cold steady and unsteady flow. Figure 26 shows a picture of the experiment at the steady flow test rig and the results of the modelling of the DPF tests. Figure 26(a) plots the pressure drop across the DPF and evidences the good agreement between the experimental and modelled pressure drop in a wide range of flow regime, which is defined by the Reynolds number (Re) at the inlet of the DPF. Additionally, Figure 26(b) shows the decomposition of the pressure drop across the DPF into the different mechanisms taking part. As found in literature [32][33], the non-inertial pressure drop, which occurs inside the monolith channels, is the most important contribution at low Re and losses weight with respect to the inertial contributions as Re increases. The inertial pressure drop at the inlet cross-section of the DPF is around half of the pressure drop at the outlet cross-section, also in agreement with literature data.

TABLE 2

\section{FIGURE 7}

The characterization of every of the pressure drop contributions across the DPF under steady flow conditions was applied to model tests under impulsive flow. The comparison between experiments and modelling is shown in Figure 27 for two pressure pulses generated in an impulse flow test rig [34]. The incident pressure (dashed grey line) at the inlet of the DPF was imposed to the model. It avoids from the need of modelling the whole test rig. The model predicted both the reflected and the transmitted pressure waves. The results indicate the ability of the model to reproduce with accuracy the flow dynamic behaviour of the DPF under highly unsteady flow. This analysis strengthens the 
robustness and reliability of the used numerical tools even under the exigent conditions imposed by a full-load transient process.

\section{FIGURE 8}

The prediction of the expansion process at the turbine is essential for the reproduction of the engine response under full-load transient operation. Hence, the temperature at the outlet of the DPF has to be accurately determined in the case of the pre-turbo DPF placement, since this temperature coincides with the turbine inlet temperature. Nevertheless, the model does not consider chemical reactions. It is expected that this simplification of the model slightly under predicts the DPF outlet temperature and therefore the energy recovered in the turbine. The heat transfer affecting the DPF is also a key issue to take into consideration because of the influence when simulating the DPF placement upstream of the turbine. A nodal heat transfer model for the DPF, which is presented in the Appendix, was applied at this work. The nodal model solves the heat transfer equation both in the axial and radial direction of the monolith channels. The radial heat transfer from the monolith to the metal can and to the environment are also included [35]. The model was derived and adapted to the monolith geometry from the proposal of Galindo et al. [36] for the calculation of heat transfer in ducts during transient processes of turbocharged diesel engines.

Figure 28 shows the comparison between experimental data and modelled results under hot pulsating flow conditions. Experimental data were obtained testing the DPF in a heavy-duty engine test bench. The engine was run at different engine speeds and low equivalence ratio to prevent the influence of the DPF loading on the warm-up and the final steady state conditions at the DPF.

The inlet flow pressure and temperature and the outlet flow pressure were imposed to the model in order to predict the mass flow through the DPF and the temperature at the outlet of the DPF. The results of such a prediction are shown in Figure 28 for every of the operating points tested. The comparison with experimental data presents again a good agreement and confirms the robustness and accuracy of the DPF model for the study of the fluid-dynamic behaviour of the DPF under a wide range of engine conditions.

Page 11 of 49 
FIGURE 9

\section{Analysis of the DPF placement influence}

The placement of the DPF upstream of the turbine has several effects on the engine performance that are closely related to the turbocharger response but also on the DPF working conditions. The main interest in this exhaust line architecture lays on the increase of the mean thermal level in the DPF. It would give rise to better and more frequent conditions for passive regeneration occurrences. Furthermore, there is a second beneficial aspect that would affect the turbine operation. It is the increase of the turbine expansion ratio with respect to the DPF post-turbo placement that the preturbo DPF placement is able to yield.

FIGURE 10

This effect is sketched in the example shown in Figure 29, which reproduces the thermodynamic process of the flow depending on the DPF placement on an h-s diagram. Independently of the DPF placement, the thermodynamic conditions at point A-I are 3.5 bar and $527^{\circ} \mathrm{C}$. The DPF pressure drop and the turbine efficiency have been supposed also the same and equal to $20000 \mathrm{~Pa}$ and $55 \%$ respectively. Additionally, the DPF has been considered to behave adiabatically. In these conditions, the temperature at the inlet of the turbine would be also the same for both exhaust line configurations.

Therefore, the expansion ratio of the turbine would increase and also the specific isentropic work in the case of the pre-turbo DPF placement. Depending on the turbine efficiency, the specific work could be also higher, as plotted in Figure 29. As a consequence, the higher energy at disposal of the turbine would soften the engine control leading to better performance in terms of reduction of the fuel consumption.

Page 12 of 49 
Such an ideal process has one critical factor with respect to the real behaviour in the heat loss taking place at the DPF. This phenomenon generally results in the decrease of the temperature at the inlet of the turbine in the pre-turbo DPF placement. Nevertheless, it would be also required to add the influence of the pressure drop across the DPF, which will not remain the same when changing the DPF placement. On the one hand, it is because of the different flow conditions at the inlet of the DPF. On the other hand the soot loading level in the DPF would be different during normal engine operation being expected to be lower in the case of the pre-turbo DPF placement because of the higher thermal level and the higher occurrence of self regeneration events in the DPF.

The influence on the engine performance of the trade-off between the heat loss and the pressure drop across the DPF is analyzed in this section by means of the simulation of full-load transient operation at $2500 \mathrm{rpm}$. On the one hand, this sort of simulation allows the evaluation of the influence of the exhaust line architecture at steady state full-load conditions. On the other hand, the additional effects imposed by restrictive aspects like the thermal inertia of the DPF, the turbocharger lag or the engine control (VGT opening, boost control, etc.), which are key for a comprehensive understanding of the engine dynamic response, are also considered under very exigent engine requirements.

\subsection{Engine response under clean DPF conditions}

The first stage of the study has comprised the comparison of the engine response under the assumption of clean DPF placed both downstream and upstream of the turbine. The pre-turbo DPF configuration of the engine is shown in Figure 30, which represents the engine layout in OpenWAM's interface for its gas dynamic simulation.

The simulated transient process is described in Figure 31(a) by means of the throttle position as function of the time, which is the actuator used to impose the required engine load. At the beginning of the simulation the engine was stabilized at full-load steady state conditions. The only objective of this phase is to obtain confident steady wall temperature at all engine components, including the DPF. This objective is reached neglecting the heat capacity of the different materials what speeds up the convergence of the heat transfer model [36]. Thus, the engine was brought down to zero-load after $1.5 \mathrm{~s}$ and the injected fuel mass was reduced from $58.3 \mathrm{mg} / \mathrm{cc}$ to $4.2 \mathrm{mg} / \mathrm{cc}$ whichever the DPF 
placement, as shown in Figure 31(d). The phase at zero-load took $1.9 \mathrm{~s}$, which approximately corresponds to the duration of a gear change but keeping constant the engine speed. From this phase up to the end of the simulation the wall temperature was calculated accounting for the heat capacity of the materials in order to consider the effect of the thermal inertia of the engine components. Finally, the engine throttle was pushed up to $100 \%$ to begin with the full-load transient process, which lasted until the engine performance stabilization at steady-state conditions.

\section{FIGURE 11}

Figure 31(b) represents the engine torque during the whole transient process considering clean DPF conditions. The maximum value of the engine torque is $291 \mathrm{Nm}$ if the DPF is placed downstream of the turbine. However, the pre-turbo DPF configuration provides a maximum torque of $283.5 \mathrm{Nm}$. Due to the fact that the injected fuel mass is the same in both cases at full-load steady state conditions, as shown in Figure 31(d), the BSFC of the engine has increased a $2.6 \%$ in the case of the pre-turbo DPF placement.

Nevertheless, in spite of this worse performance of the pre-turbo DPF configuration, the dynamics of the engine transient response is very similar. Whichever the exhaust line architecture, the $90 \%$ of the maximum torque of the DPF post-turbo configuration is reached at the same time. The reason for this response obeys to the fact that the starting conditions of the full-load acceleration $(\mathrm{t}=3.4 \mathrm{~s})$ are better in the case of the DPF pre-turbo configuration, as the representation of the air mass flow indicates in Figure 31(c).

The air mass flow at the beginning of the full-load acceleration is $17.2 \%$ higher in the case of the DPF pre-turbo configuration. Therefore, the boost control allows greater initial fuel mass injection. However, this advantage disappears as the acceleration process advances due to the lower rate of air mass flow increase. As a consequence, it also produces lower rate of fuel mass injection and slightly slows down the engine transient response. Finally, the air mass flow is the same at steady state conditions for both engine configurations and allows the maximum injection of fuel mass. Therefore, the equivalence ratio is also the same at these conditions. 
FIGURE 12

\subsubsection{Analysis of the turbocharger operation}

Several phenomena are responsible of the engine behaviour described in Figure 31. They mainly determine the energy available for the turbine, whose behaviour is shown in Figure 32. The intake pressure is represented in Figure 32(a). It is the control parameter of the VGT response during the full-load transient process, as explained in section 2. The behaviour of the pressure is analogous to that shown by the air mass flow. Its target value at full-load steady state conditions is 2.31 bar at $2500 \mathrm{rpm}$. This value is clearly obtained before for the post-turbo DPF configuration in spite of the higher initial value that corresponds to the pre-turbo DPF configuration at the beginning of the fullload transient process.

The initial better conditions of the pre-turbo DPF configuration are produced by the higher gas temperature at the inlet of the turbine, which is represented in Figure 32(c), during the zero-load phase. It is caused by the high heat accumulation capacity of the DPF substrate, which heats the gas flow when the engine decelerates. Consequently, the energy at disposal of the turbine is higher in comparison with the post-turbo DPF configuration and the turbocharger deceleration is more attenuated, as the turbocharger speed confirms in Figure 32(d). In this way, the intake pressure and the air mass flow remains also greater. Additionally, on the one hand, at the beginning of the transient process the greater air mass flow gives rise to greater pressure at the turbine inlet when the DPF is placed upstream of the turbine, even including the DPF pressure drop, as Figure 32(b) shows. This fact feeds back the process since it leads to higher expansion ratio at the turbine (Figure 32(e)) besides to the higher temperature. Additionally, on the other hand, the VGT position, which is represented in Figure 32(f), remains constant and is the same for every engine configuration during the zero-load phase. Consequence of it and of the higher expansion ratio, the turbine efficiency also slightly increases and contributes to the slower deceleration of the turbocharger.

FIGURE 13

Page 15 of 49 
However, the thermal inertia of the DPF is also responsible of the increasing influence that the turbocharger lag has on the engine transient response in the case of the pre-turbo DPF configuration. During the acceleration, the thermal transient of the DPF controls the engine response. When the throttle is pushed up $100 \%$, the VGT fully closes. The injected fuel mass increases and then the turbocharger accelerates leading to the increase of the air mass flow, which feeds up the process. However, the pre-turbo DPF configuration shows a limited temperature at the inlet of the turbine because of the DPF thermal transient. Accordingly, the energy available in the turbine is lower in comparison with the post-turbo DPF configuration. Although the initial conditions were better, the described phenomenon turns into lower rate of air mass flow increase and then into a lower injection rate of fuel mass, which feeds downs the process becoming it slower than the response of the engine with the post-turbo DPF configuration, as previously shown in Figure 31.

As regard the steady state conditions, the target intake pressure is reached before in the case of the post-turbo DPF configuration, so that the VGT starts its opening at time $5.25 \mathrm{~s}$. The engine control regulates the VGT opening in order to converge to the target intake pressure. An intermediate opening of the VGT improves its efficiency. Thus, the VGT remains partially open and results in the decrease of the pressure at the inlet of the turbine. Consequently, the pumping work of the engine is reduced and the maximum torque can be attained.

By contrast, the pre-turbo DPF configuration is influenced by the heat loss to the environment across the DPF once reached the steady state conditions. It gives rise to lower turbine inlet temperature than in the case of the post-turbo configuration. Hence the VGT opening is slower and remains closer at steady state conditions with respect to the post-turbo DPF configuration, as Figure 32(f) shows. In this way, the engine control compensates the lower turbine inlet temperature with a clearly higher expansion ratio, which is represented in Figure 32(e). However, the higher pressure in the exhaust manifold when the DPF is placed upstream of the turbine means higher pumping work. Therefore, the pre-turbo DPF configuration is not able to develop the same maximum torque than the post-turbo DPF configuration.

At steady state conditions, it is also interesting the analysis of the flow conditions at the inlet of the turbine depending on the DPF placement. Figure 33 shows the instantaneous flow conditions at the 
inlet of the turbine in the last calculated engine cycle. This information complements the conclusions obtained from analysis of the mean values.

The DPF attenuates the pulses both with regard to the pressure, which is shown in Figure 33(a), and the temperature, which becomes a quasi-steady magnitude because of the heat transfer across the DPF, as Figure 33(b) indicates. As a consequence of this filtering phenomenon, the pre-turbo DPF configuration becomes a constant pressure turbocharging system instead of a pulse turbocharging and has to offset the loss of energy associated to the flow pulses keeping the VGT closer. Figure 33(c) represents the isentropic power available for the turbine and clearly shows the loss of energy associated to the pulse peaks. As the air mass flow is essentially the same independently of the DPF placement (Figure 31(c)), the turbine inlet pressure is higher for the pre-turbo DPF configuration because of the lower VGT opening. Also because of the VGT position, the turbine efficiency is lower, as Figure 33(d) plots. Because of the lower turbine efficiency, the mean isentropic power available for the turbine has to be slightly higher than in the case of the DFP post-turbo configuration (in both configurations the compressor works at the same conditions). The balance is obtained by the engine control, which sets the VGT opening so that the turbine develops the required work.

In spite of the drawbacks caused by the loss of energy at the inlet of the turbine in the case of the pre-turbo DPF configuration, it is important to highlight that the extreme filtering of the pulses across the DPF ensures that the turbine behaves in a quasi-steady way. The instantaneous relation between the efficiency and the blade speed ratio shown in Figure 33(d) confirms that the range of operation of the turbine has been reduced. The possibility of working at optimum efficiency in every operating condition of the engine turns this behaviour into a benefit regarding the optimization of the turbine matching.

\section{FIGURE 14}

\subsubsection{Analysis of the DPF operation}

The whole overview of the engine response is completed with the analysis of the DPF behaviour, which is shown in Figure 34. Plot (a) confirms the expected great potential that the placement of the 
DPF upstream of the turbine brings in terms of improvement for passive regeneration conditions. The inlet DPF temperature has varied from $490{ }^{\circ} \mathrm{C}$ to $665^{\circ} \mathrm{C}$ at full-load steady state conditions at $2500 \mathrm{rpm}$. Therefore, the increase of temperature experimented at the DPF reaches to $175^{\circ} \mathrm{C}$ for the same conditions of equivalence ratio, which is 0.76 , and ensures suitable conditions for high rate of reaction of thermal regeneration.

The magnitude of the temperature increase means the existence of more engine operating points in which similar conditions may be attained. It would reduce the need of active regeneration strategies and the mean soot loading in the DPF, which would become into lower pressure drop across the DPF.

With respect to the pressure drop, Figure 34(b) represents the cycle averaged stagnation pressure drop across the DPF versus the cycle averaged dynamic pressure at the inlet of the DPF. The ratio between these magnitudes is defined as the pressure drop coefficient. The value of this magnitude tends to be asymptotic at high Re, as the quasi-constant slope of series in Figure 34(b) evidences. Figure 34(b) shows that the dynamic pressure at the inlet of the DPF is lower in the case of the preturbo DPF configuration. The reason explaining it is that upstream of the turbine, the gas density is higher than downstream of it. Therefore, the velocity diminishes since both the inlet cross-section of the DPF and the mass flow are the same for both configurations. Since the dynamic pressure depends linearly of the gas density but squarely of the velocity, its value diminishes at the inlet of the DPF when it is placed upstream of the turbine. As consequence, the pressure drop across the clean DPF is also lower in this configuration.

\section{FIGURE 15}

\subsection{Influence of DPF loading on engine response}

The analysis of the thermodynamic processes of the flow depending on the exhaust line architecture leads to conclude that the lower pressure drop across the DPF is, the higher expansion ratio is in the turbine when the DPF is placed upstream of the it, as can be inferred from Figure 29. Although the effect of the improvement of the expansion ratio exists, it has been not commented in section 4.1 
because is lessened by the thermal behaviour of the DPF and ends to be hidden by the VGT opening control.

Although at clean DPF conditions the advantage of the pre-turbo DPF configuration in terms of turbine expansion ratio does not control the engine response, as the DPF is loaded this aspect takes importance.

Figure 35 shows the pressure drop across the DPF during full-load transient operation at $2500 \mathrm{rpm}$ for different soot loading conditions of the DPF. The soot loading of $2 \mathrm{~g} / \mathrm{m}^{2}$ corresponds to the transient from deep bed filtration to cake filtration regime and the case of $5 \mathrm{~g} / \mathrm{m}^{2}$ takes into account the existence of the particulate layer on the channel porous walls. As shown, the trends of the DPF pressure drop dependence with its placement in the exhaust line are kept independently of the soot loading.

FIGURE 16

Figure 36 shows the torque and the expansion ratio to evaluate the engine performance as function of the DPF placement and the soot loading. Figure 36(a) shows the torque provided by the postturbo DPF configuration, which appears to be very sensitive to the soot loading, i.e. to the DPF pressure drop. Even for a low soot loading, the post-turbo DPF configuration suffers a decrease of the torque at steady state conditions. As a consequence, the maximum torque is lower than that obtained with the pre-turbo DPF configuration, which is shown in Figure 36(b). In fact, the torque in the pre-turbo DPF configuration scarcely varies with DPF soot loading.

Most damaging assumptions for the pre-turbo DPF configuration were assumed regarding the thermal behaviour of the DPF. In this sense, on the one hand, it was considered that possible regeneration did not take place. Therefore, the effect of the corresponding heat release on the turbine inlet temperature was neglected. On the other hand, the thermal properties of the porous substrate were considered not to be affected by the soot loading. Soot particulate has very low thermal conductivity [37] and then the convection heat transfer between the gas and the inlet channel walls would be reduced if their properties were applied in the calculation. Therefore, the Page 19 of 49 
assumptions prevent from the increase of the gas temperature upstream of the turbine that would take place.

Therefore, the differences found in the engine response are explained by the variations of the expansion ratio in the turbine since the thermal behaviour of the DPF has been not modified with respect to clean DPF conditions. Figure 36(c) represents the expansion ratio in the case of the postturbo DPF configuration. When the DPF is clean the energy available in the turbine is very high. It allows the engine control to open the VGT reducing the expansion ratio. However, the dynamic response of the engine with soot loading of only $2 \mathrm{~g} / \mathrm{m}^{2}$ becomes slower because of the reduction of the expansion ratio of the turbine. Therefore, the work obtained in the turbine decreases and the engine control cannot open it up to time $13 \mathrm{~s}$, as shown in Figure 36(e). In the case of a soot loading of $5 \mathrm{~g} / \mathrm{m}^{2}$, the engine response is clearly slower and the turbine is even not opened during the duration of the simulation. It indicates that the target intake pressure has been not reached and the engine performance becomes dramatically affected.

On the contrary, Figure 36(d) shows that the expansion ratio is very similar with independence of the DPF soot loading in the case of the pre-turbo DPF configuration. The engine transient response is only slightly slowed down because of the higher pressure drop across the DPF, as the expansion ratio of the turbine indicates between time $4 \mathrm{~s}$ and $6 \mathrm{~s}$ of the transient simulation. The consequence is that the opening of the VGT, which is shown in Figure 36(f) for the pre-turbo DPF configuration, takes place from time $11 \mathrm{~s}$ instead of at time $7 \mathrm{~s}$, which corresponds to clean DPF conditions. Nevertheless the engine performance is kept with high independence of the DPF soot loading due to the benefits on the expansion ratio that the pre-turbo DPF configuration brings and offsets the drawback derived from the heat loss across the DPF.

\section{FIGURE 17}

\section{Summary and conclusions}

An analysis of the influence that the DPF placement upstream of the turbine has on the engine and DPF operation has been presented. The engine operating conditions have covered full-load transient 
operation at constant engine speed and the study has been performed on the basis of simulation with a $1 \mathrm{D}$ gas dynamics codes.

The engine of reference for simulations has been previously modelled with experimental data corresponding to steady state and full-load transient operation conditions. It has led to obtain a robust setup of the engine model with emphasis on combustion simulation and engine control for reliable simulation under transient operation. The set of numerical tools has been completed with a DPF model for wall-flow monoliths thoroughly formulated to properly treat unsteady compressible flow characteristic in the exhaust manifold of turbocharged diesel engines. The DPF incorporated into the engine model has been also independently modelled and validated with a sample of experimental data corresponding to several flow conditions.

On the one hand, the results have confirmed the high potential of the pre-turbo DPF configuration regarding the enhancement of the flow conditions to increase the rate of passive regeneration occurrences. It would mean lower penalty on BSFC due to late injection or other active regeneration strategies and even lower dependence on fuel additives and catalysts. Additionally, the mean soot loading between active regeneration events would be expected to be lower. Consequently, the penalty on fuel consumption derived from an excessive DPF pressure drop could be also lessened. On the other hand, it has to take into account that the pre-turbo DPF configuration ensures the VGT operation free of soot and also enables the development of clean EGR of short/medium route.

The engine response when the DPF is placed upstream of the turbine is a function of the trade-off between the thermal behaviour of the DPF and the improvement regarding higher enthalpy drop at the turbine and lower DPF pressure drop. Furthermore, the flow downstream the DPF becomes quasi-steady, so that constant pressure turbocharging takes place in the case of the pre-turbo DPF placement for every engine operation condition. This phenomenon means the loss of the dynamic energy of the flow but allows an easier optimization of the turbocharged engines matching. In any case, this is a key aspect since directly affects the selection and design of the turbine as a component.

As main drawback has appeared the need of suitable thermal management of the DPF to face thermal losses and thermal inertia effects on the engine response. These phenomena can give rise to the need of VGT closing, which results into higher pumping work.

Page 21 of 49 
Nevertheless, consequences of thermal losses are in part offset by the increase of the expansion ratio in the pre-turbo DPF configuration. This effect is more and more beneficial as the DPF is loaded when comparing with the traditional post-turbo DPF configuration, whose performance have shown to be very sensitive to DPF soot loading because of the degradation of the turbine expansion ratio. An additional advantage of the pre-turbo DPF placement is the reduction of the pressure drop across the DPF for the same engine operation conditions than the post-turbo DPF placement. It is caused by the higher density of the gas through the DPF. This fact involves that the dimensions of the DPF could be reduced, so that its weight and cost would be also decreased. It would mean a decrease of the DPF heat losses leading to a reduction of such a drawback for the temperature upstream of the turbine. Additional measures to deal with thermal lag may be explored from different perspectives. The development of ceramic materials able for soot filtration and with lower heat capacity, the use of two-stages or pressure-wave turbocharger technology or the thermal insulation of the DPF [14] are potential solutions that may be tackled.

\section{REFERENCES}

[1] Regulation (EC) $n^{\circ} 715 / 2007$ of the European Parliament and of the Council of 20 June 2007 on type approval of motor vehicles with respect to emissions from light passenger and commercial vehicles (Euro 5 and Euro 6) and on access to vehicle repair and maintenance information. Official Journal of the European Union, June 2007.

[2] Johnson, T.V. Review of diesel emissions and control. International Journal of Engine Research, 2009, 10(5), 275-285.

[3] Howitt, J., Montierth, M. Cellular ceramic diesel particulate filter. SAE Technical Paper 81104, 1981.

[4] Outland, R.J. Ceramic filters for diesel exhaust particulates. US Patent nº 4,276,071 (General Motors), 1981.

[5] Konstandopoulos, A.G., Kostoglou, M., Vlachos, N. and Kladopoulou, E. Advances in the science and technology of diesel particulate filter simulation. Advances in Chemical Engineering, 2007, 33, 284-294.

Page 22 of 49 
[6] Murtagh, M.J. Diesel particulate filters (DPF): A short course. In Diesel particulate and NOx emissions course, Ann Arbor, MI, 2002, University of Leeds.

[7] Khair, M.G. A review of Diesel particulate filter technologies. SAE Technical Paper 200301-2303, 2003.

[8] Ogyu, K., Ohno, K., Hong, S. and Komori, T. Ash storage capacity enhancement of diesel particulate filter. SAE Technical Paper 2004-01-949, 2004.

[9] Nakatani, K., Hirota, S., Takeshima, S., Itoh, K., Tanaka, T. and Dohmae, K. Simultaneous PM and NOx reduction system for diesel engines. SAE Technical Paper 200201-0957, 2002.

[10] Hirata, K., Masaki, N., Yano, M., Akagawa, H., Takada, K., Kusaka, J. and Mori, T. Development of an improved urea-selective catalytic reduction-diesel particulate filter system for heavy-duty commercial vehicles, International Journal of Engine Research, 2009, 10(5), $337-348$.

[11] Lorentzou, S., Pagkoura, C., Konstandopoulos, A.G. and Boettcher, J. Advanced catalyst coatings for diesel particulate filters. SAE Technical Paper 2008-01-0843, 2008.

[12] Law, M.C., Clarke, A., and Garner, C.P. The effects of soot properties on the regeneration behavior of wall-flow diesel particulate filters. Proceedings of the Institution of Mechanical Engineers, Part D: Journal of Automobile Engineering, 2004, 218(12), 1513-1524.

[13] Hanamura, K., Karin, P., Cui, L., Rubio, P., Tsuruta, T., Tanaka, T. and Suzuki, T. Micro- and macroscopic visualization of particulate matter trapping and regeneration processes in wall-flow diesel particulate filters, International Journal of Engine Research, 2009, 10(5), 305-321.

[14] Payri, F., Desantes, J.M., Galindo, J. and Serrano, J.R. Exhaust manifold of a turbocharged reciprocating internal combustion engine (text in spanish). Patent application P200900482. Priority date 13/02/2009. Oficina Española de Patentes y Marcas (2009).

Page 23 of 49 
[15] Windsor R.E. and Baumgard, K.J. Internal combustion engine with dual particulate traps ahead of turbocharger. Patent application Publication, US 2009/0151328 A1, United States, February 2009.

[16] Konstandopoulos, A.G., Skaperdas, E., Warren, J. and Allansson, R., Optimized filter design and selection criteria for continuously regenerating diesel particulate traps. SAE Technical Paper 1999-01-0468, 1999.

[17] Bisset, E.J. Mathematical model of the thermal regeneration of a wall-flow monolith diesel particulate filter, Chemical Engineering Science, 1984, 39(7-8), 1233-1244.

[18] Subramaniam, M.N., Joergl, V., Keller, P., Weber, O., Toyoshima, T. and Vogt, C.D. Feasibility assessment of a pre-turbo after-treatment system with a 1D modelling approach. SAE Technical Paper 2009-01-1276, 2009.

[19] Cunningham, P. and Meckl, P. 1-D dynamic diesel particulate filter model for unsteady pulsating flow, SAE Technical Paper 2007-01-1140, 2007.

[20] Piscaglia, F. and Ferrari, G. A novel 1D approach for the simulation of unsteady reacting flows in Diesel exhaust after-treatment systems. Energy, 2009, 34(12), 2051-2062.

[21] Torregrosa, A.J., Serrano, J.R., Arnau, F.J. and Piqueras, P. A fluid dynamic model for unsteady compressible flow in wall-flow Diesel particulate filters. Energy, 2011, 36, 671-684.

[22] Desantes, J.M., Serrano, J.R., Arnau, F.J. and Piqueras, P. Derivation of the method of characteristics for the fluid dynamic solution of flow advection along porous wall channels. Submitted to Applied Mathematical Modelling, 2010.

[23] Payri, F., Benajes, J., Galindo, J. and Serrano, J.R. Modelling of turbocharged Diesel engines in transient operation. Part 2: Wave action models for calculating the operation in a High Speed Direct Injection engine. Proceedings of the Institution of Mechanical Engineers, Part D: Journal of Automobile Engineering, 2002, 216(D5), 431-442.

[24] Galindo, J., Serrano, J.R., Arnau, F.J. and Piqueras, P. Description and analysis of a onedimensional gas-dynamic model with independent time discretization. In ASME Internal Combustion Engine Division 2008 Spring Technical Conference, Chicago, 2008.

Page 24 of 49 
[25] Openwam website, CMT-Motores Térmicos (Universidad Politécnica de Valencia). www.openwam.org, 2010.

[26] Serrano, J.R., Arnau, F.J., Dolz, V., Tiseira, A. and Cervelló, C. A model of turbocharger radial turbines appropriate to be used in zero- and one-dimensional gas dynamics codes for internal combustion engine modelling. Energy Conversion and Management, 2008, 49, 37293745 .

[27] Rakopoulos, C.D. and Glakoumis, E.G. Sensitivity analysis of transient diesel engine simulation. Proceedings of the Institution of Mechanical Engineers, Part D: Journal of Automobile Engineering, 2006, 220(1), 89-101.

[28] Serrano, J.R., Climent, H., Guardiola, C. and Piqueras, P. Methodology for characterisation and simulation of turbocharged diesel engines combustion during transient operation. Part 2: Phenomenological combustion simulation. Applied Thermal Engineering, 2009, 29(1), 150-158.

[29] Serrano, J.R., Arnau, F.J., Dolz, V. and Piqueras, P. Methodology for characterisation and simulation of turbocharged diesel engines combustion during transient operation. Part 1: Data acquisition and post-processing. Applied Thermal Engineering, 2009, 29(1), 142-149.

[30] Payri, F., Galindo, J., Serrano, J.R. and Arnau, F.J. Analysis of numerical methods to solve one-dimensional fluid-dynamic governing equations under impulsive flow in tapered ducts. International Journal of Mechanical Science 2004 46(7), 981-1004.

[31] Benson, R.S. The thermodynamics and gas dynamics of internal-combustion engines, volume 1. Clarendon Press, New York, 1982.

[32] Konstandopoulos, A.G., Skaperdas, E. and Masoudi, M. Inertial contributions to the pressure drop of Diesel particulate filters. SAE Technical Paper 2001-01-0909, 2001.

[33] Masoudi, M. Hydrodynamics of Diesel particulate filters. SAE Technical Paper 2002-011016, 2002.

Page 25 of 49 
[34] Payri, F., Desantes, J.M. and Broatch, A. Modified impulse method for the measurement of the frequency response of acoustic filters to weakly nonlinear transient excitations. Journal of the Acoustical Society of America, 2000, 107(2), 731-738.

[35] Piqueras, P. Contribution to thermo-and fluid dynamic modelling of wall-flow diesel particulate filters (text in spanish). PhD thesis, Universidad Politécnica de Valencia, 2010.

[36] Galindo, J., Luján, J.M., Serrano, J.R., Dolz, V. and Guilain, S. Description of a heat transfer model suitable to calculate transient processes of turbocharged diesel engines with one-dimensional gas-dynamic codes. Applied Thermal Engineering, 2006, 26(1), 66-76.

[37] Haralampous, O. and Koltsakis, G.C. Intra-layer temperature gradients during regeneration of diesel particulate filters. Chemical Engineering Science, 2002, 57(13) 2345-2355.

\section{ACKNOWLEDGMENTS}

This work has been partially supported by the Spanish MCI Grant DPI2010-20891-C02-02.

\section{NOMENCLATURE}

OD

zero-dimensional

$1 \mathrm{D}$

one-dimensional

$2 \mathrm{D}$

bi-dimensional

BMEP break mean effective pressure

BSFC balance specific fuel consumption

C equivalent thermal capacity

DPF Diesel particulate filter

$e_{0} \quad$ specific stagnation internal energy

ECU engine control unit

Page 26 of 49 


\begin{tabular}{|c|c|}
\hline EGR & exhaust gas recirculation \\
\hline$F$ & cross section area \\
\hline$F_{w}$ & momentum transfer coefficient for square channels \\
\hline$h_{0}$ & specific stagnation enthalpy \\
\hline HRL & heat release law (non-dimensional) \\
\hline HSDI & high speed direct injection \\
\hline$k_{p}$ & particulate layer permeability \\
\hline$k_{w}$ & porous wall permeability \\
\hline OEM & original engine manufacturer \\
\hline$p$ & pressure \\
\hline PID & Proportional-Integral-Derivative controller \\
\hline$q$ & heat per unit of time and area \\
\hline $\mathrm{R}$ & equivalent thermal resistance \\
\hline $\operatorname{Re}$ & Reynolds number \\
\hline RoHR & rate of heat release \\
\hline SOI & start of injection \\
\hline$t$ & time dimension \\
\hline $\mathrm{T}$ & temperature \\
\hline$u$ & velocity \\
\hline$u_{w}$ & filtration velocity \\
\hline $\begin{array}{l}\text { VGT } \\
\text { rage } \angle / \text { Ui } 4 y\end{array}$ & variable geometry turbine \\
\hline
\end{tabular}




$\begin{array}{ll}w_{p} & \text { particulate layer thickness } \\ w_{w} & \text { porous wall thickness } \\ x & \text { axial dimension }\end{array}$

Greek letters

$\alpha$

honeycomb cell size

$\Delta p$

stagnation pressure drop

$\mu \quad$ dynamic viscosity

$\rho \quad$ density

\section{APPENDIX: FORMULATION OF THE 1D MODEL FOR HONEYCOMB WALL-FLOW DPF}

The 1D wall-flow DPF model solves the flow across the whole DPF device. The governing equations are formulated for non-homentropic one-dimensional unsteady compressible flow inside the monolith channels [21]:

- Mass conservation

$$
\frac{\partial\left(\rho_{i} F_{i}\right)}{\partial t}+\frac{\partial\left(\rho_{i} u_{i} F_{i}\right)}{\partial x}=(-1)^{i} 4\left(\alpha-2 w_{p} i\right) \rho_{i} u_{w_{i}}
$$

- Momentum conservation

$$
\frac{\partial\left(\rho_{i} u_{i} F_{i}\right)}{\partial t}+\frac{\partial\left(\rho_{i} u_{i}^{2} F_{i}+p_{i} F_{i}\right)}{\partial x}-p_{i} \frac{d F_{i}}{d x}=-F \mu_{i} u_{i}
$$

- Energy conservation

Page 28 of 49 


$$
\frac{\partial\left(e_{0 i} \rho_{i} F_{i}\right)}{\partial t}+\frac{\partial\left(h_{0 i} \rho_{i} u_{i} F_{i}\right)}{\partial x}=q_{i} \rho_{i} F_{i}+(-1)^{i} 4\left(\alpha-2 w_{p} i\right) h_{0 w} \rho_{i} u_{w_{i}}
$$

Subscript and superscript $i$ in equations (1), (2) and (3) identifies the type of monolith channel. It takes value 0 for the solution of the outlet channels and value 1 in the case of the inlet channels. The conservation equations in a pair of inlet and outlet channels is closed with the addition of the state equation for an ideal gas in every of the channels and the equation controlling the pressure drop across the porous medium, which allows the obtaining of the value of the filtration velocity.

In this work, the Forchheimer's effect has been neglected because of the laminar flow inside the channels. Therefore, the pressure drop is governed by the Darcy's equation. The filtration velocity at every node in the axial direction of the channel is obtained in the most general case as

$$
\begin{gathered}
u_{w_{1}}=\frac{\Delta p}{\frac{\mu w_{w}}{k_{w}} \frac{\rho_{1}\left(\alpha-2 w_{p}\right) w_{w}}{\rho_{0} \alpha}+\frac{\mu\left(\alpha-2 w_{p}\right)}{2 k_{p}} \ln \left(\frac{\alpha}{\alpha-2 w_{p}}\right)} \\
u_{w_{0}}=\frac{u_{w_{1}} \rho_{1}\left(\alpha-2 w_{p}\right)}{\rho_{0} \alpha}
\end{gathered}
$$

where $\Delta p$ is the stagnation pressure drop between the inlet and the outlet channel, which is obtained from the solution of the conservation equations, as suggested also in Figure 37. This solution has been obtained assuming that the filtration velocity may vary between the porous wall surface of the inlet channels and that of the outlet channels. The reason is the possible existence of the particulate layer and the assumed linear variation of the channel width represented in Figure 37.

FIGURE 18

As an additional assumption was taken that the flow is uniform at the inlet cross-section of the monolith (but time-dependant). Therefore, the flow has the same behaviour in all the pairs of inlet and outlet channels and only one of them needs to be solved. The solution of the governing Page 29 of 49 
equations in the internal nodes of the channels is performed with the two-step Lax\&Wendroff method. Its formulation is adapted to couple the solution of the governing equations systems of the inlet and the outlet channels by means of the Darcy's law [22]. The boundary conditions of the channels, both the junction with the inlet and the outlet cone and the plugged ends, are solved applying the method of characteristics derived for flow in porous wall channels [22]. Regarding the inlet and the outlet cones, which are treated as 0D elements, their solution is obtained by means of a filling and emptying model.

The heat transfer in the DPF is solved by means of a nodal approach. Two nodal schemes are considered. Figure 38(a) shows the nodal scheme for the calculation of the porous wall temperature. On every axial location where the flow properties are solved inside the inlet and outlet channels, there are three nodes for the calculation of the porous wall temperature: on the interface between the porous wall (or the particulate layer if exists) and the inlet channel $\left(\mathrm{T}_{\mathrm{k}, 1}{ }^{\mathrm{H}}\right)$; in the middle of the porous wall $\left(\mathrm{T}_{\mathrm{k}, 2}{ }^{\mathrm{H}}\right)$; and in the interface between the porous wall and the outlet channel $\left(\mathrm{T}_{\mathrm{k}, 3}{ }^{\mathrm{H}}\right)$. The model considers the heat transfer due to conduction and convection by means of equivalent thermal resistances $(\mathrm{R})$ in the radial direction of the porous wall. The axial conduction is also considered in the middle node $(\mathrm{k}, 2)$. An equivalent thermal capacity $(\mathrm{C})$, which is defined by the properties of the material, is included in every node to account for the thermal inertia effects during transient operation. Finally, the model includes the radial heat transfer in the monolith. It can be discretized into several channels beams, which are identified by index H. Between two channels beams is defined an equivalent thermal resistance that controls the radial conductive heat transfer. It allows also taking into account the heat transfer between the monolith and the environment through the canister, as represented in the nodal scheme of Figure 38(b). Three nodes are considered in the canister for the calculation of the wall temperature in its radial direction along the different layers. The scheme evaluates: the conduction between the monolith and the canister in the last channels beam; the conduction in the solid layers, as the thermal insulator or the metal can; the radiation, conduction and convection in the air gap if exists; and the convection and radiation of the metal can and the environment. The axial conduction in the metal can and the thermal inertia of every node are also evaluated in this case by means of the corresponding equivalent thermal resistances and capacities.

\section{FIGURE 19}

Page 30 of 49 


\section{LIST OF TABLES}

Table 1.- Basic characteristics of the engine.

Table 2.- Geometrical specification of the modelled DPF.

\section{LIST OF FIGURES}

Figure 1.- Engine scheme in OpenWAM's interface with post-turbo DPF placement. The arrow on every $1 \mathrm{D}$ element indicates the positive flow sense of the numerical solution.

Figure 2.- Comparison between experimental data and modelled results under steady state conditions.

Figure 3.- Control strategy for the simulation of full-load transient operation at constant engine speed.

Figure 4.- HRL prediction for several steady state operating conditions and comparison with experimental data.

Figure 5.- Comparison between experimental data and modelled results during full-load transient operation at $1500 \mathrm{rpm}$ and $2500 \mathrm{rpm}$.

Figure 6.- Scheme of the DPF model in OpenWAM's interface.

Figure 7.- Characterization of the DPF pressure drop under cold steady flow.

Figure 8.- Results of the characterization of the DPF pressure drop under cold impulsive flow for two excitations of different peak amplitude (48 and 165 mbar) and duration (14 and $25 \mathrm{~ms}$ ).

Figure 9.- Comparison between experimental and modelled results regarding mass flow and DPF outlet temperature under hot pulsating flow conditions.

Figure 10.- Thermodynamic processes in the turbine and the DPF depending on the exhaust line architecture.

Page 31 of 49 
Figure 11.- Engine scheme in OpenWAM's interface with pre-turbo DPF placement. The arrow on every $1 \mathrm{D}$ element indicates the positive flow sense of the numerical solution.

Figure 12.- Modelling of the engine response under full-load transient operation at $2500 \mathrm{rpm}$ and clean DPF conditions.

Figure 13.- Modelling of the turbocharger behaviour under full-load transient operation at 2500 rpm and clean DPF conditions.

Figure 14.- Modelling results representing the instantaneous operation of the turbine at full-load steady state conditions at $2500 \mathrm{rpm}$ and clean DPF conditions.

Figure 15.- Modelling of the DPF behaviour under full-load transient operation at $2500 \mathrm{rpm}$ and clean DPF conditions.

Figure 16.- Modelling of the pressure drop across the DPF under full-load transient operation at $2500 \mathrm{rpm}$ as function of the DPF placement and the soot loading conditions of the DPF.

Figure 17.- Modelling of the dependence of the engine performance and the turbine expansion ratio under full-load transient operation at $2500 \mathrm{rpm}$ as function of the DPF placement and the soot loading conditions of the DPF.

Figure 18.- Axial and cross-section geometry of channels in wall-flow DPF monoliths.

Figure 19.- Nodal schemes of the DPF heat transfer model: (a) in the porous wall, (b) in the canister of the monolith.

Page 32 of 49 
Table 3.- Basic characteristics of the engine.

Type of engine

Swept volume

Number of cylinders

Bore

Stroke

Compression ratio

Maximum power (at speed)

Number of valves

Injection system

Turbocharger

EGR

Charge cooling
HSDI diesel passenger car engine

$2091 \mathrm{~cm}^{3}$

4 in line

$86 \mathrm{~mm}$

$90 \mathrm{~mm}$

17.4:1

$100 \mathrm{~kW}(4000 \mathrm{rpm})$

4 per cylinder

Common-rail

VGT

Yes

Yes

Table 4.- Geometrical specification of the modelled DPF.

\begin{tabular}{lcc}
\hline Length & $\mathrm{m}$ & 0.2 \\
Diameter & $\mathrm{m}$ & 0.132 \\
Volume & $\mathrm{cm}^{3}$ & 2740 \\
Plug length & $\mathrm{mm}$ & 3.2 \\
Cell density & $\mathrm{cpsi}$ & 200 \\
Filter cell size & $\mathrm{mm}$ & 1.486 \\
Wall thickness & $\mathrm{mm}$ & 0.31 \\
Permeability & $\mathrm{m}^{2}$ & $2.485 \times 10^{-13}$ \\
Number of channels & - & 4246 \\
Filtration area & $\mathrm{m}^{2}$ & 2.5 \\
Inlet volume & $\mathrm{cm}^{3}$ & 500 \\
Outlet volume & $\mathrm{cm}^{3}$ & 450 \\
\hline
\end{tabular}

Page 33 of 49 


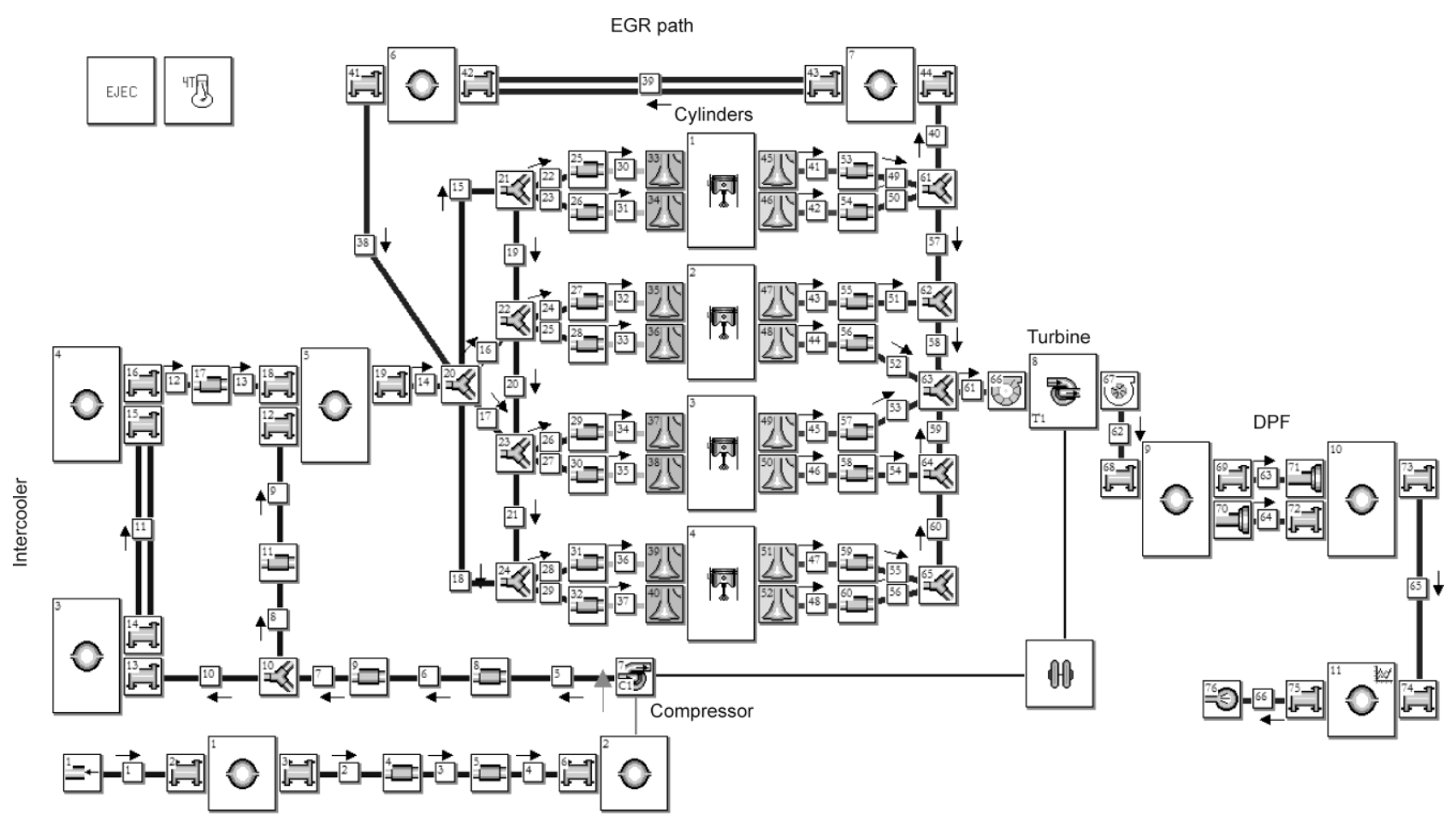

Figure 20.- Engine scheme in OpenWAM's interface with post-turbo DPF placement. The arrow on every $1 \mathrm{D}$ element indicates the positive flow sense of the numerical solution.

Page 34 of 49 
- 6 bar BMEP - $2500 \mathrm{rpm}$

- 6 bar BMEP - $2000 \mathrm{rpm}$

$+\quad 4$ bar BMEP - 2250 rpm

+ 4 bar BMEP - 1500 rpm
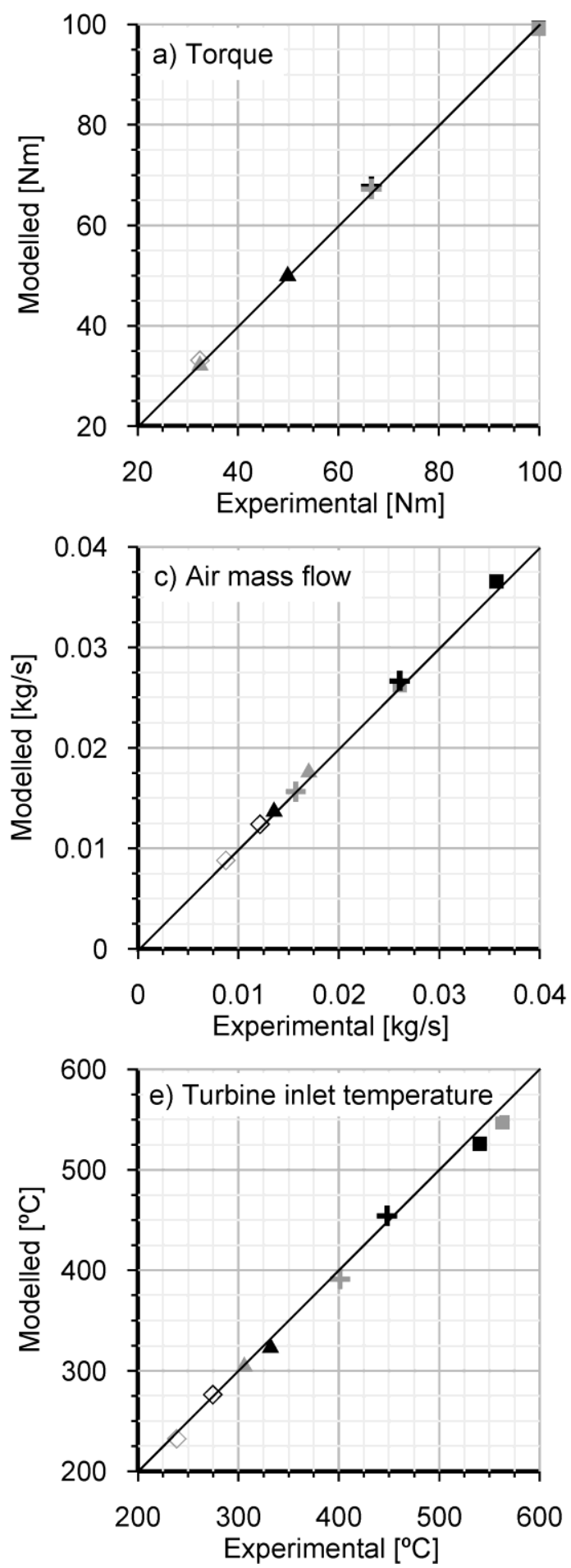

- 3 bar BMEP - $1500 \mathrm{rpm}$

- 2 bar BMEP - 2000 rpm

$\diamond \quad 2$ bar BMEP - $1500 \mathrm{rpm}$

2 bar BMEP - 1000 rpm
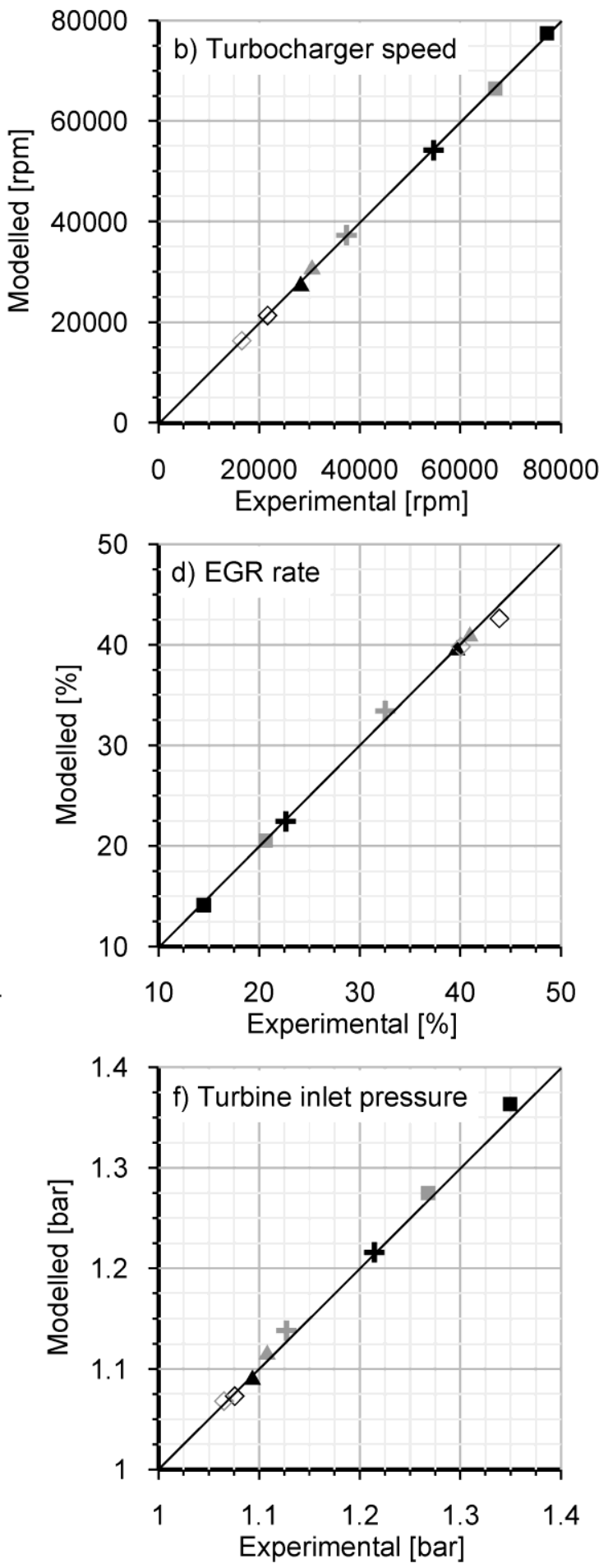

Figure 21.- Comparison between experimental data and modelled results under steady state

Page 35 of 49 conditions. 


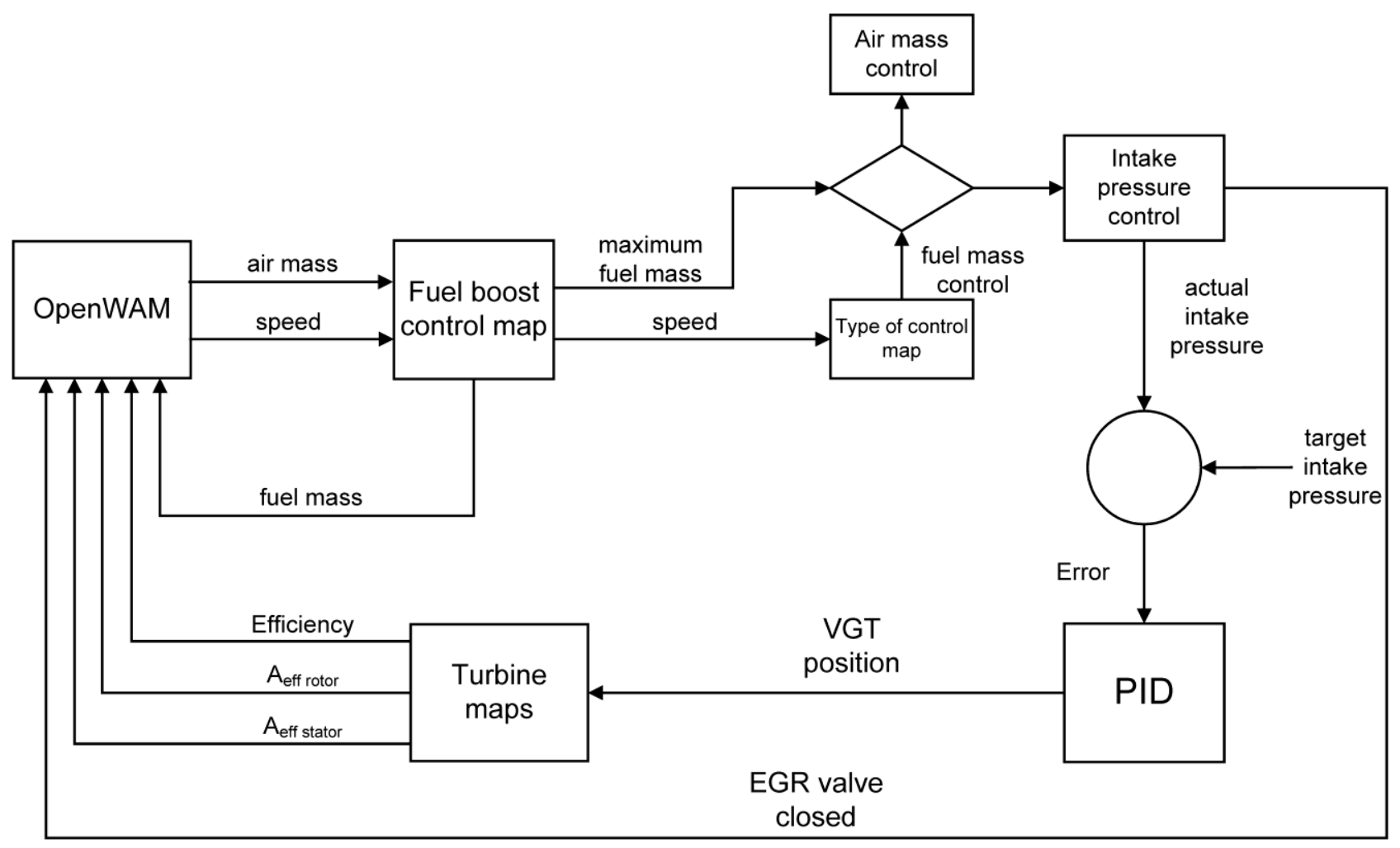

Figure 22.- Control strategy for the simulation of full-load transient operation at constant engine speed.

Page 36 of 49 

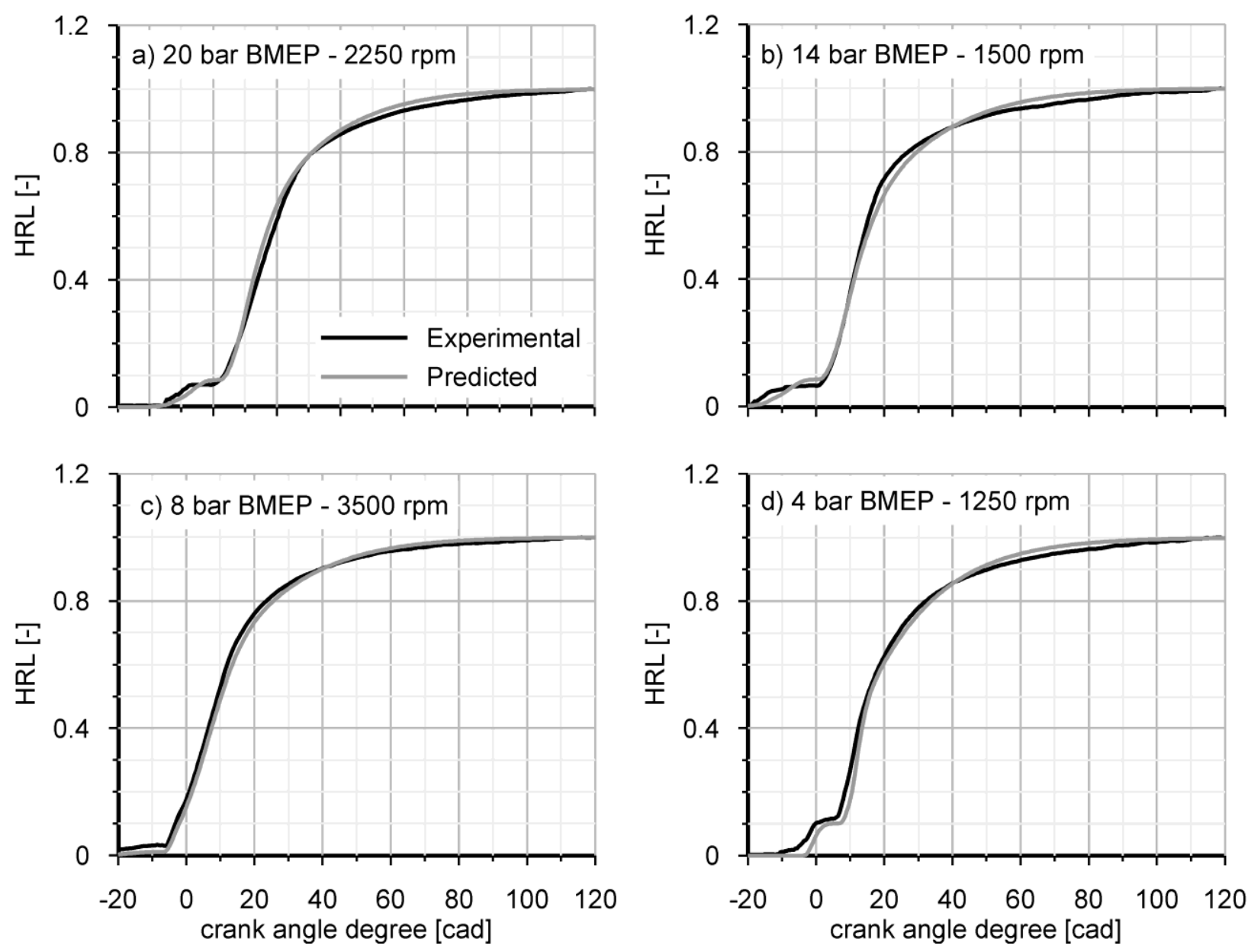

Figure 23.- HRL prediction for several steady state operating conditions and comparison with experimental data.

Page 37 of 49 

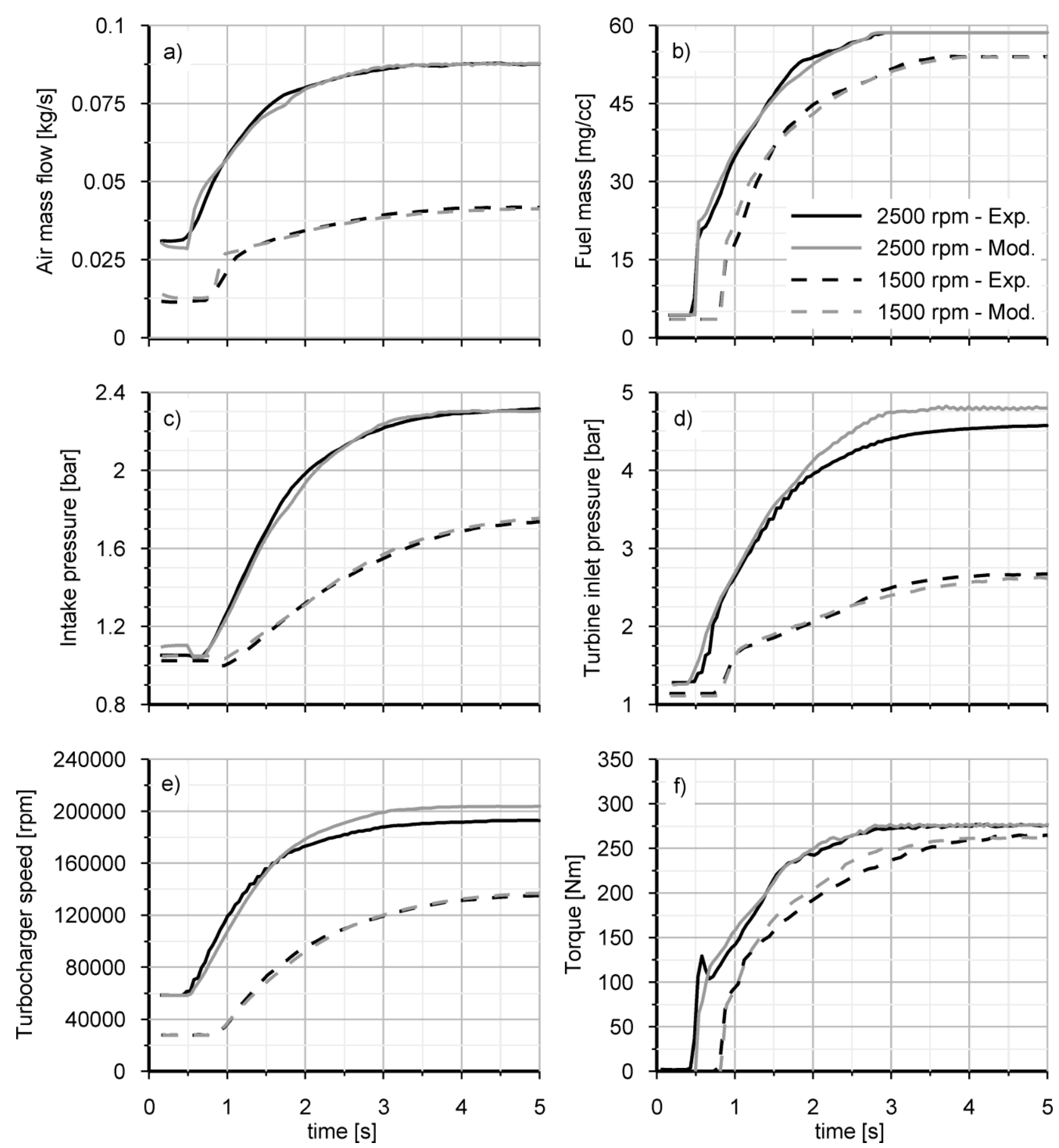

Figure 24.- Comparison between experimental data and modelled results during full-load transient operation at $1500 \mathrm{rpm}$ and $2500 \mathrm{rpm}$.

Page 38 of 49 


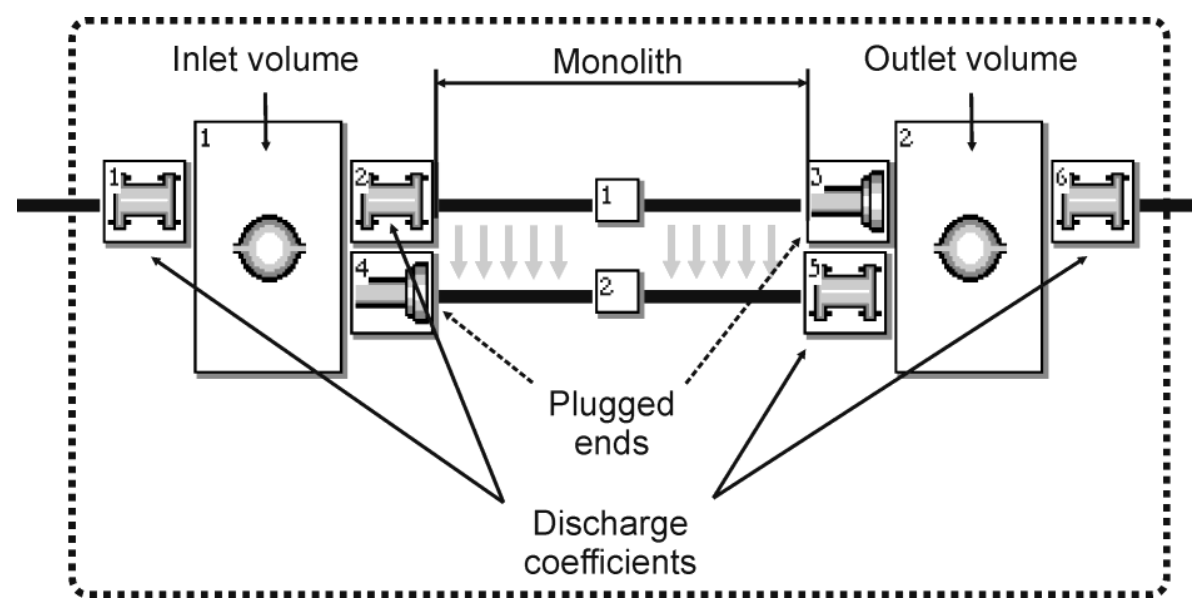

Figure 25.- Scheme of the DPF model in OpenWAM's interface. 


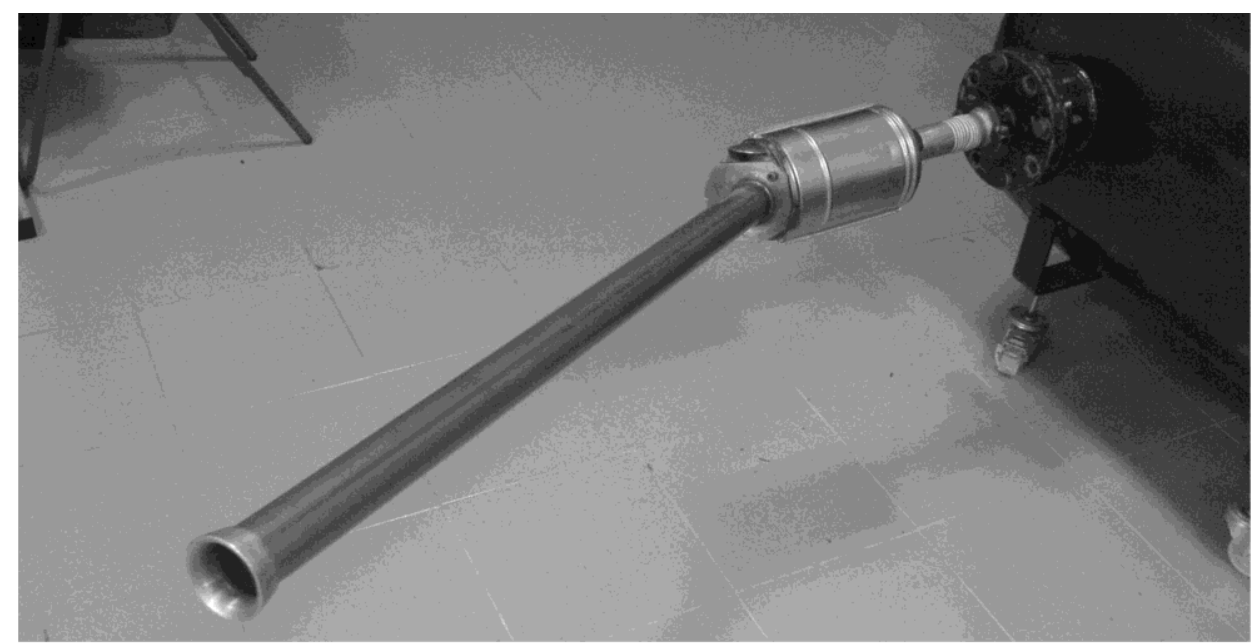

a)

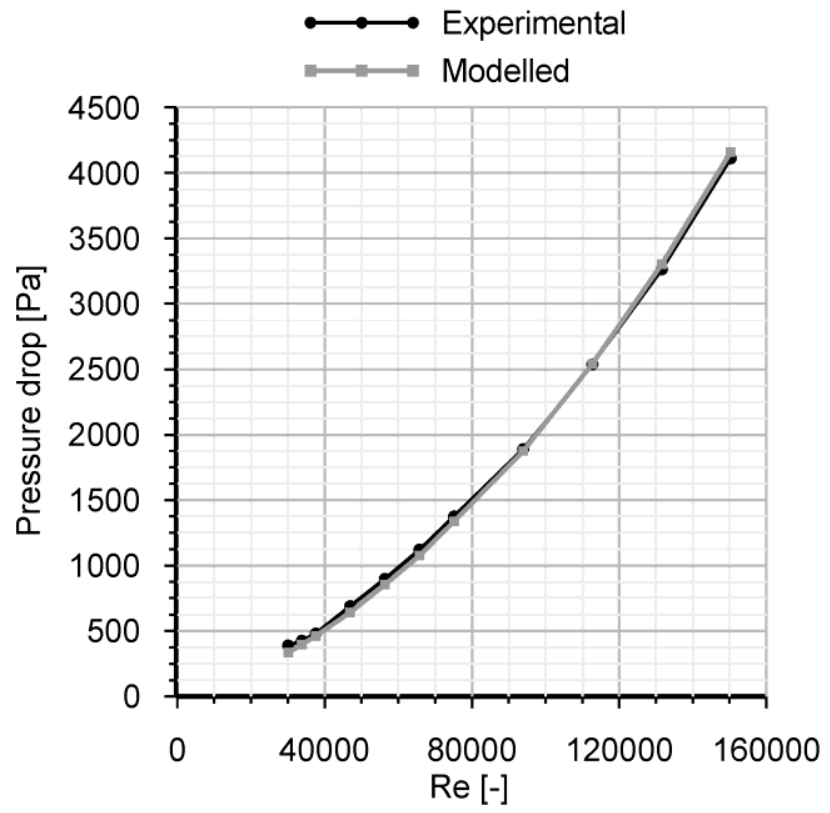

b)

$\bullet \rightarrow-\bullet$ Inlet cone

$\longrightarrow$ Monolith channel inlet

$\longrightarrow$ Channel (non-inertial)

$--\rightarrow-\rightarrow$ Monolith channel outlet

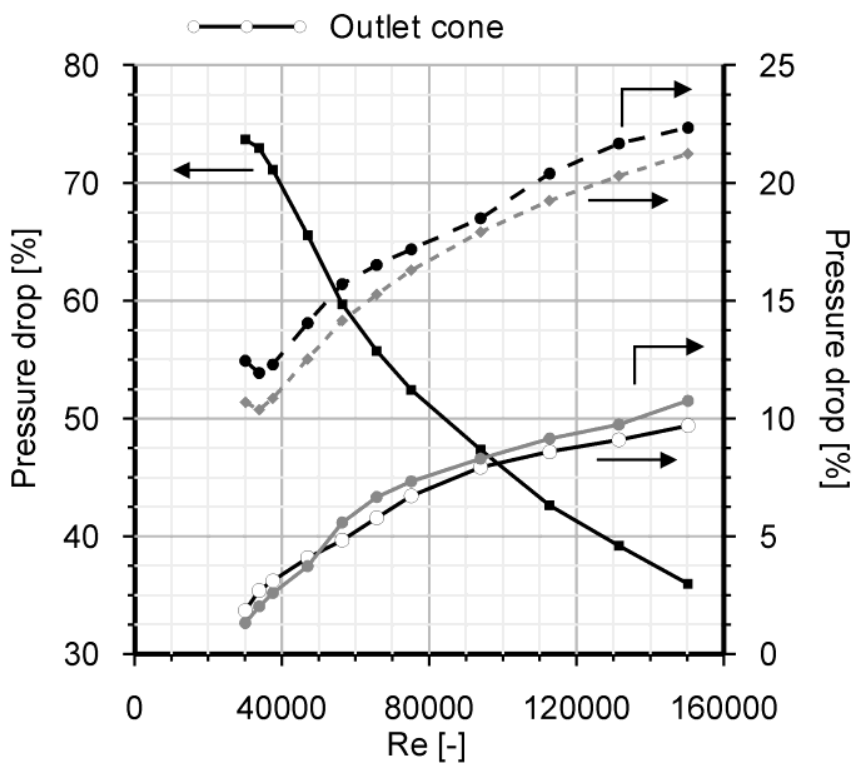

Figure 26.- Characterization of the DPF pressure drop under cold steady flow. 

a) $48 \mathrm{mbar}-14 \mathrm{~ms}$
b) $165 \mathrm{mbar}-25 \mathrm{~ms}$
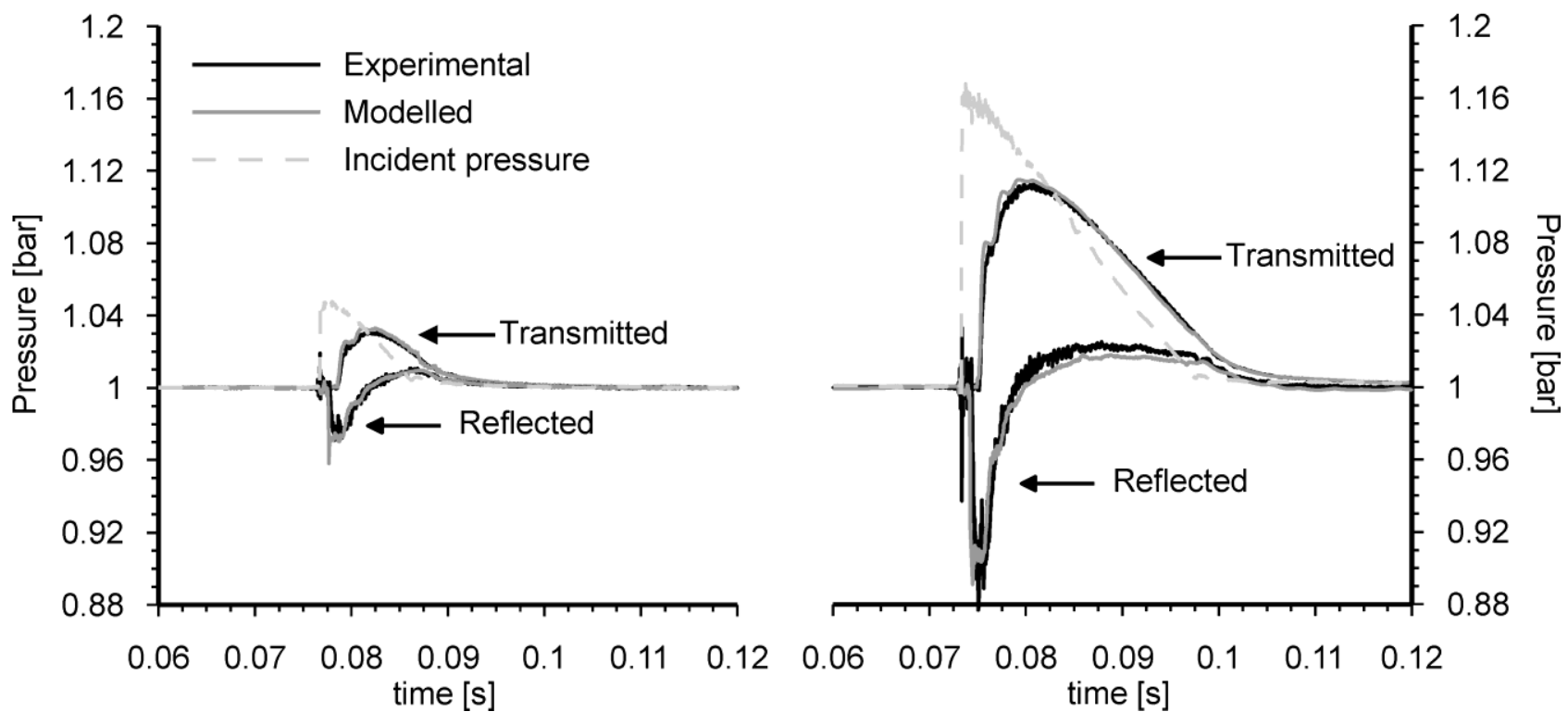

Figure 27.- Results of the characterization of the DPF pressure drop under cold impulsive flow for two excitations of different peak amplitude (48 and 165 mbar) and duration (14 and $25 \mathrm{~ms}$ ).

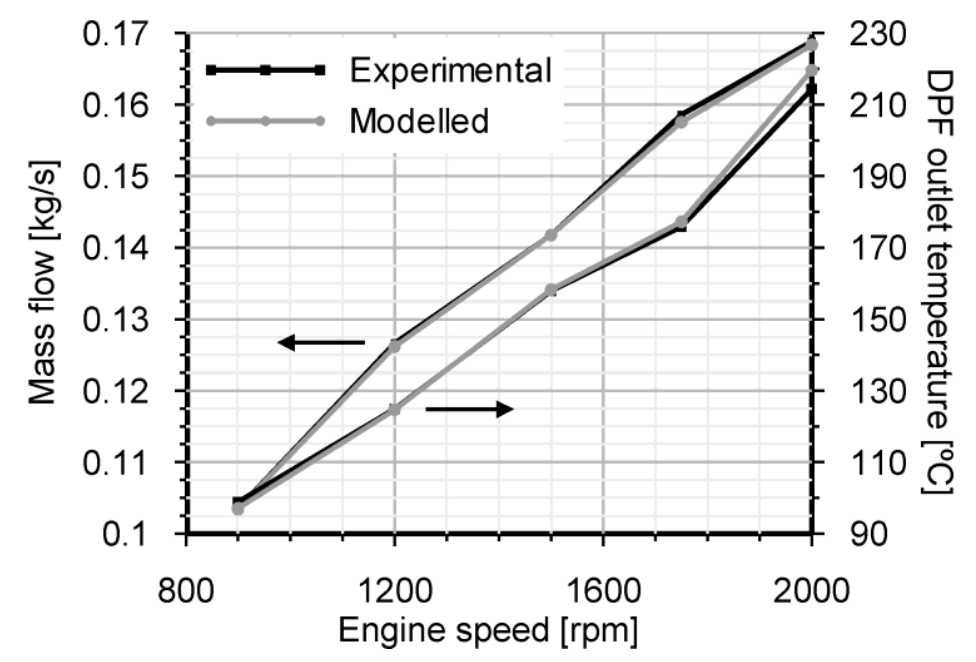

Figure 28.- Comparison between experimental and modelled results regarding mass flow and DPF outlet temperature under hot pulsating flow conditions.

Page 41 of 49 
Post-turbo DPF

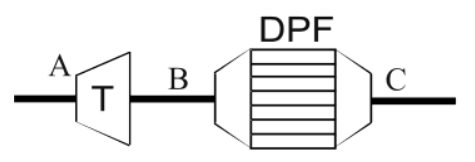

Pre-turbo DPF

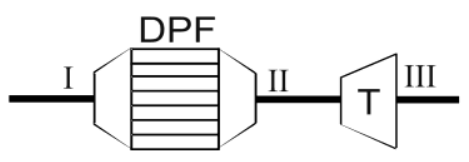

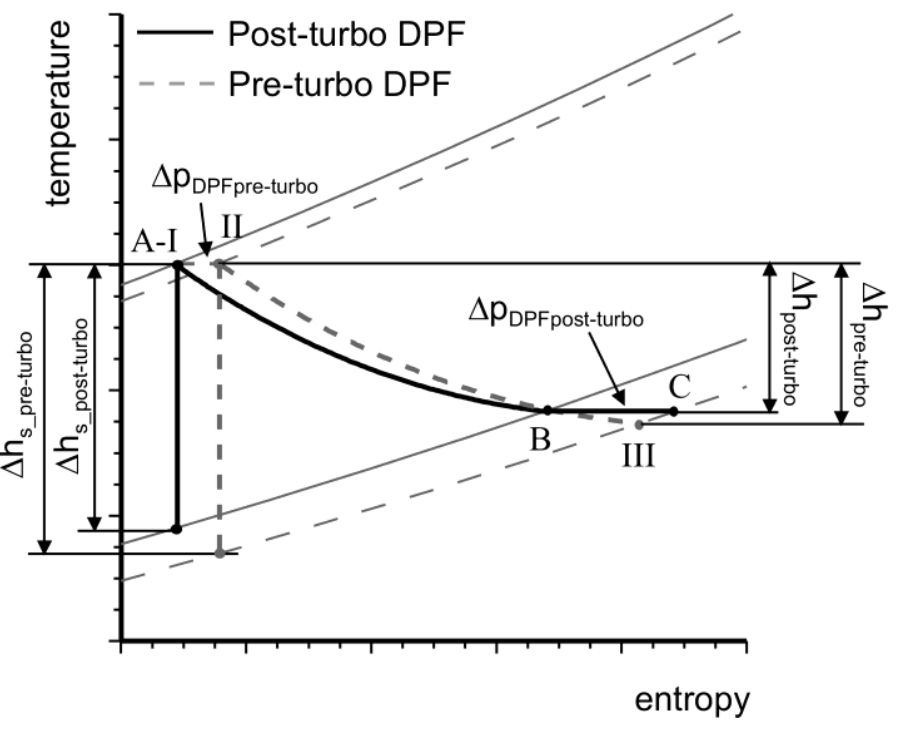

Figure 29.- Thermodynamic processes in the turbine and the DPF depending on the exhaust line architecture.

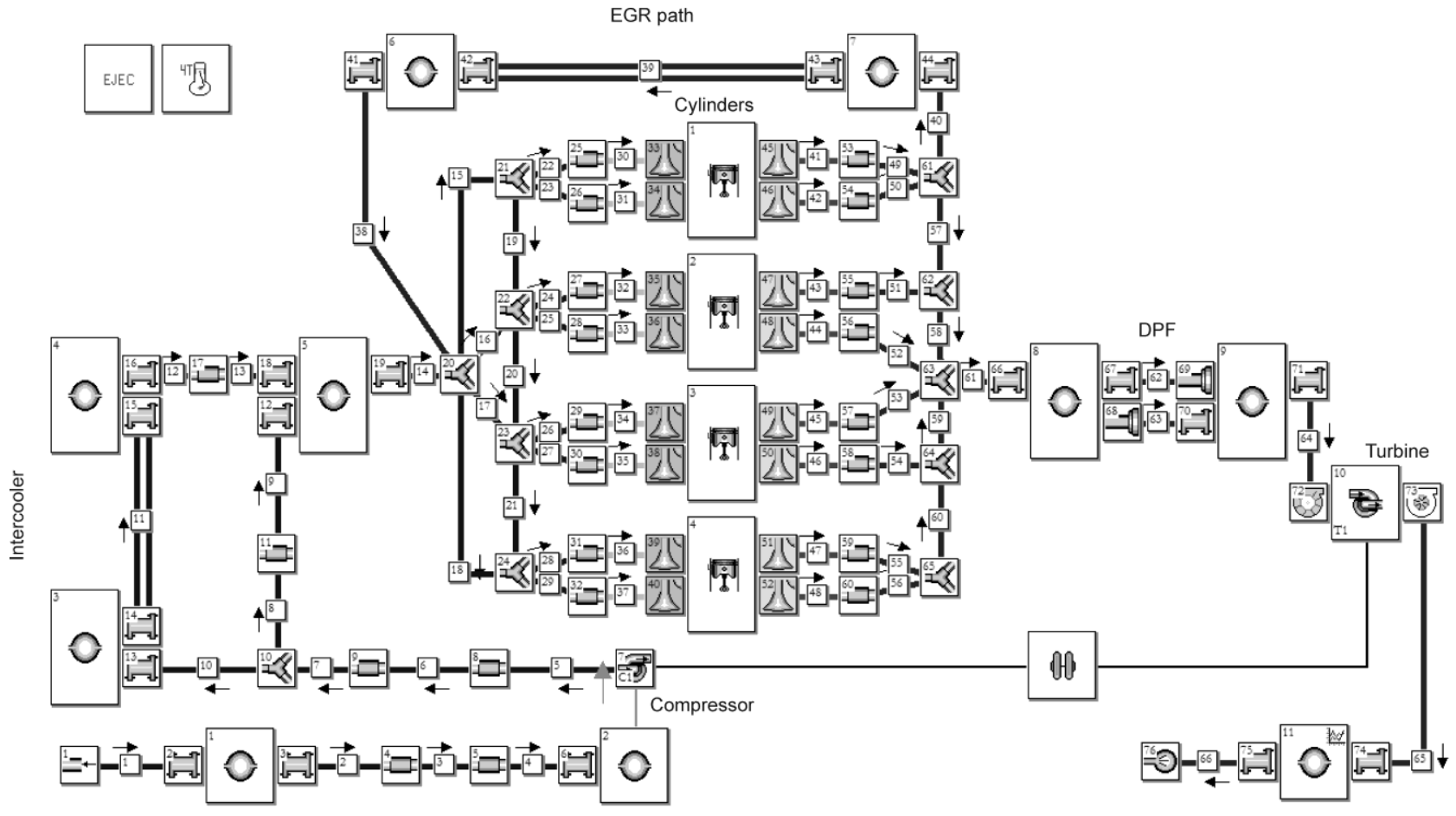

Figure 30.- Engine scheme in OpenWAM's interface with pre-turbo DPF placement. The arrow on every $1 \mathrm{D}$ element indicates the positive flow sense of the numerical solution.

Page 42 of 49 

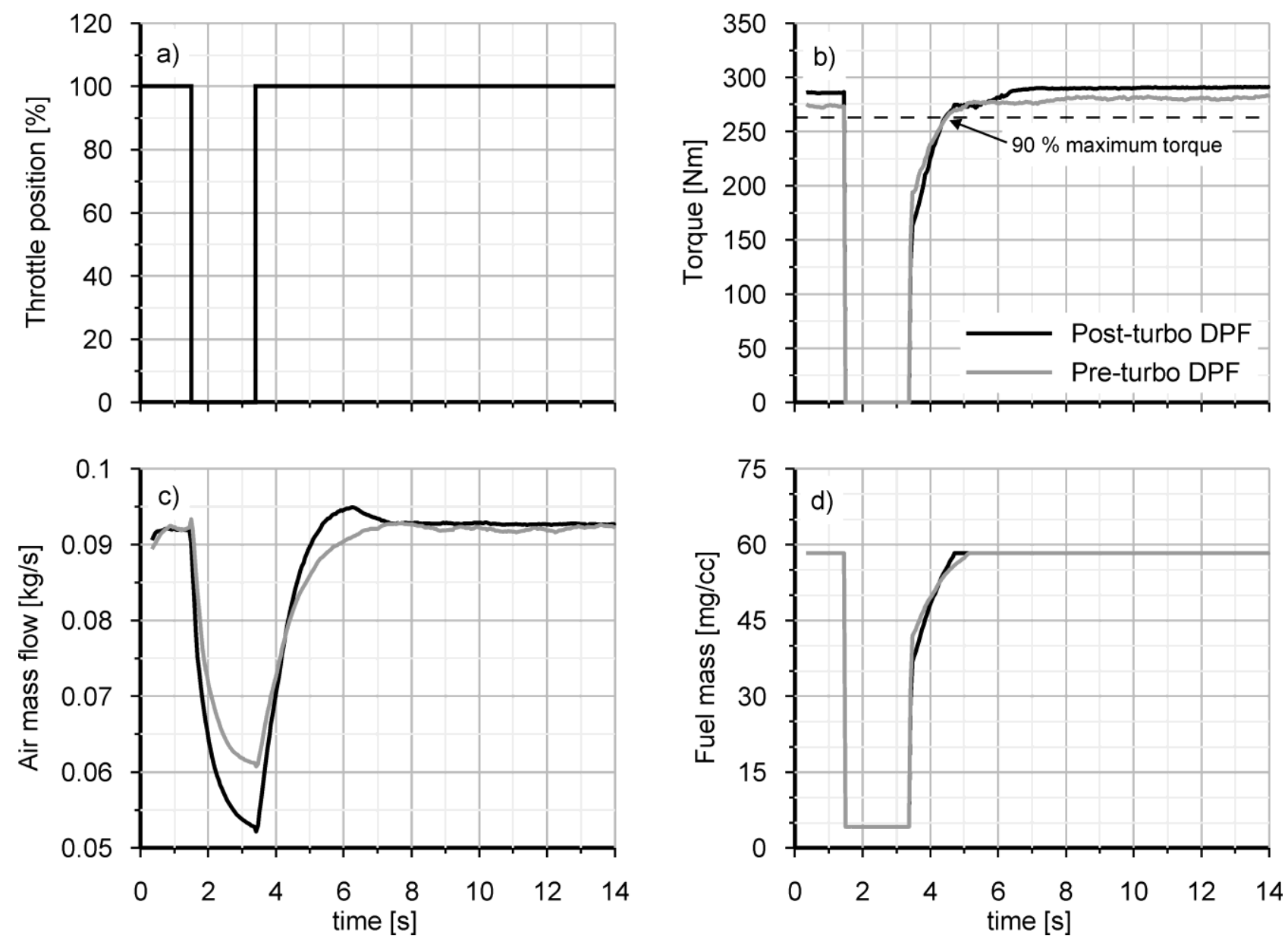

Figure 31.- Modelling of the engine response under full-load transient operation at $2500 \mathrm{rpm}$ and clean DPF conditions.

Page 43 of 49 

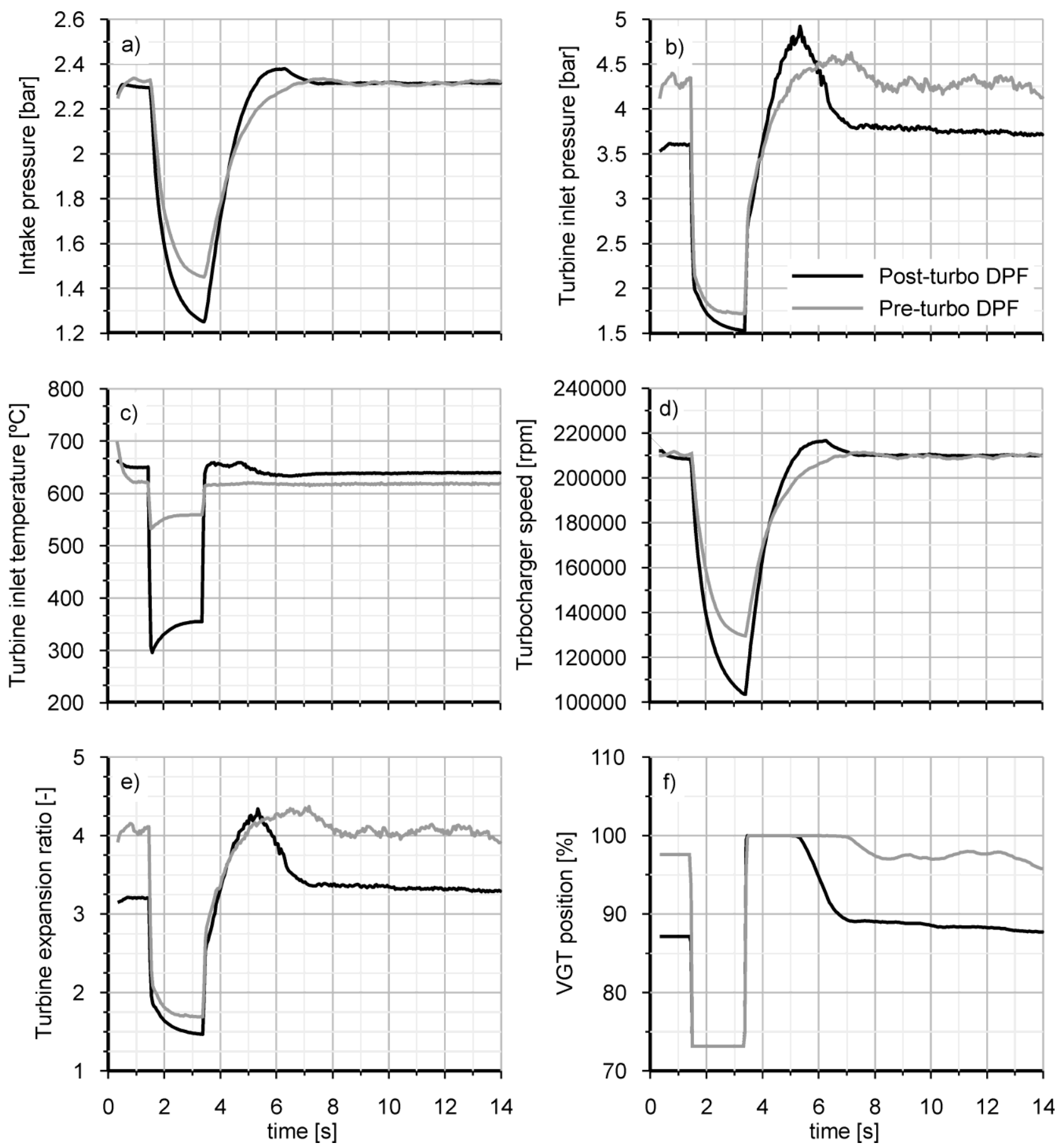

Figure 32.- Modelling of the turbocharger behaviour under full-load transient operation at 2500 rpm and clean DPF conditions.

Page 44 of 49 

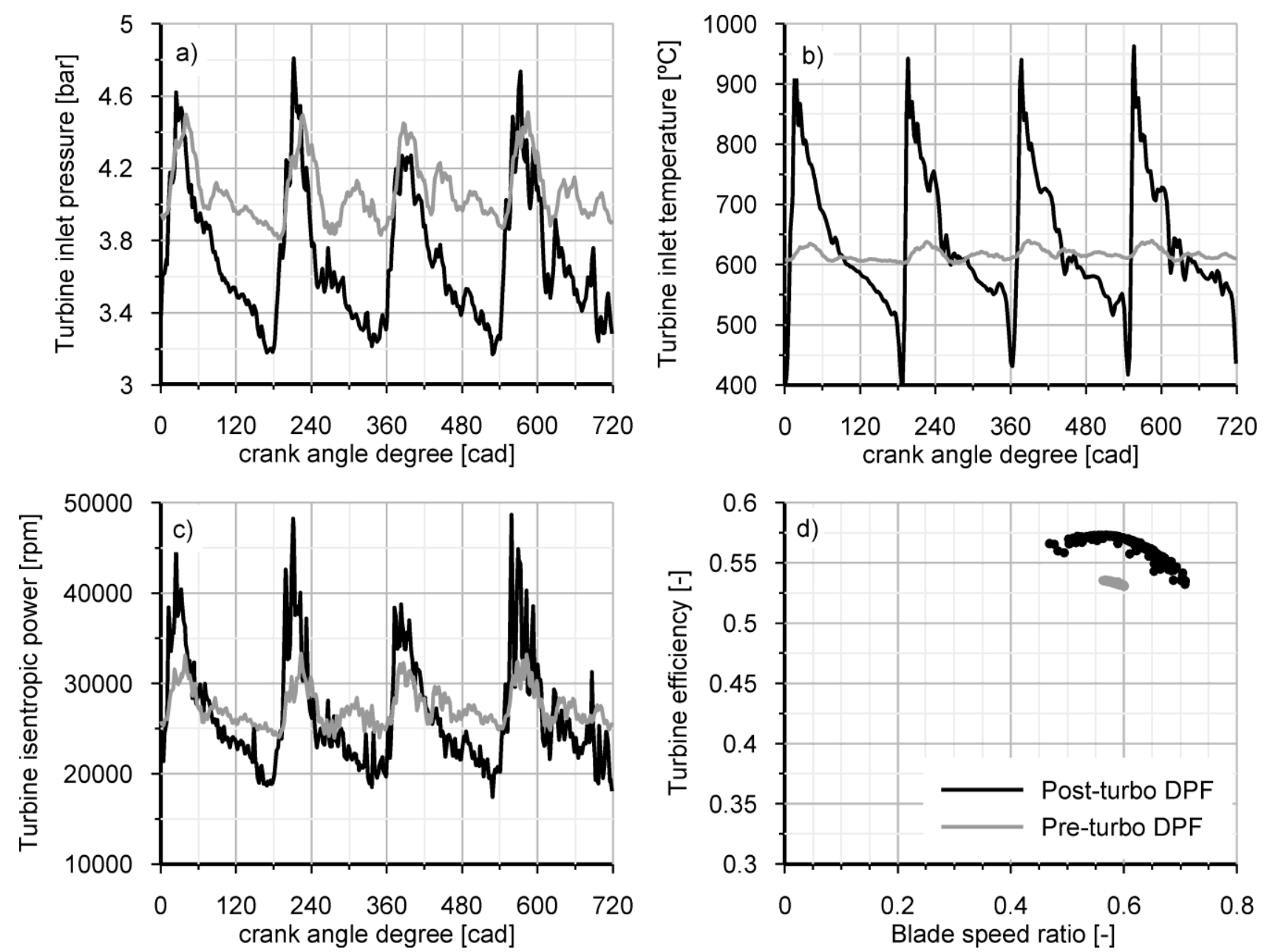

Figure 33.- Modelling results representing the instantaneous operation of the turbine at full-load steady state conditions at $2500 \mathrm{rpm}$ and clean DPF conditions.

Page 45 of 49 

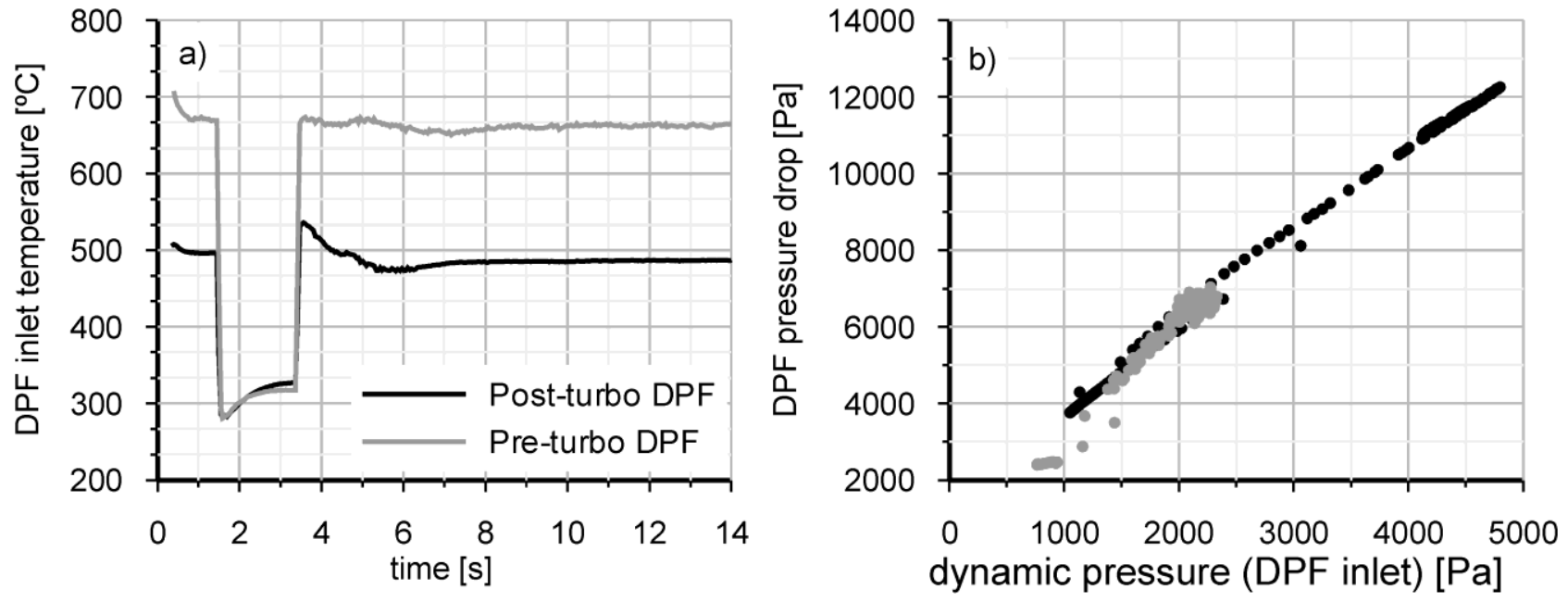

Figure 34.- Modelling of the DPF behaviour under full-load transient operation at $2500 \mathrm{rpm}$ and clean DPF conditions.
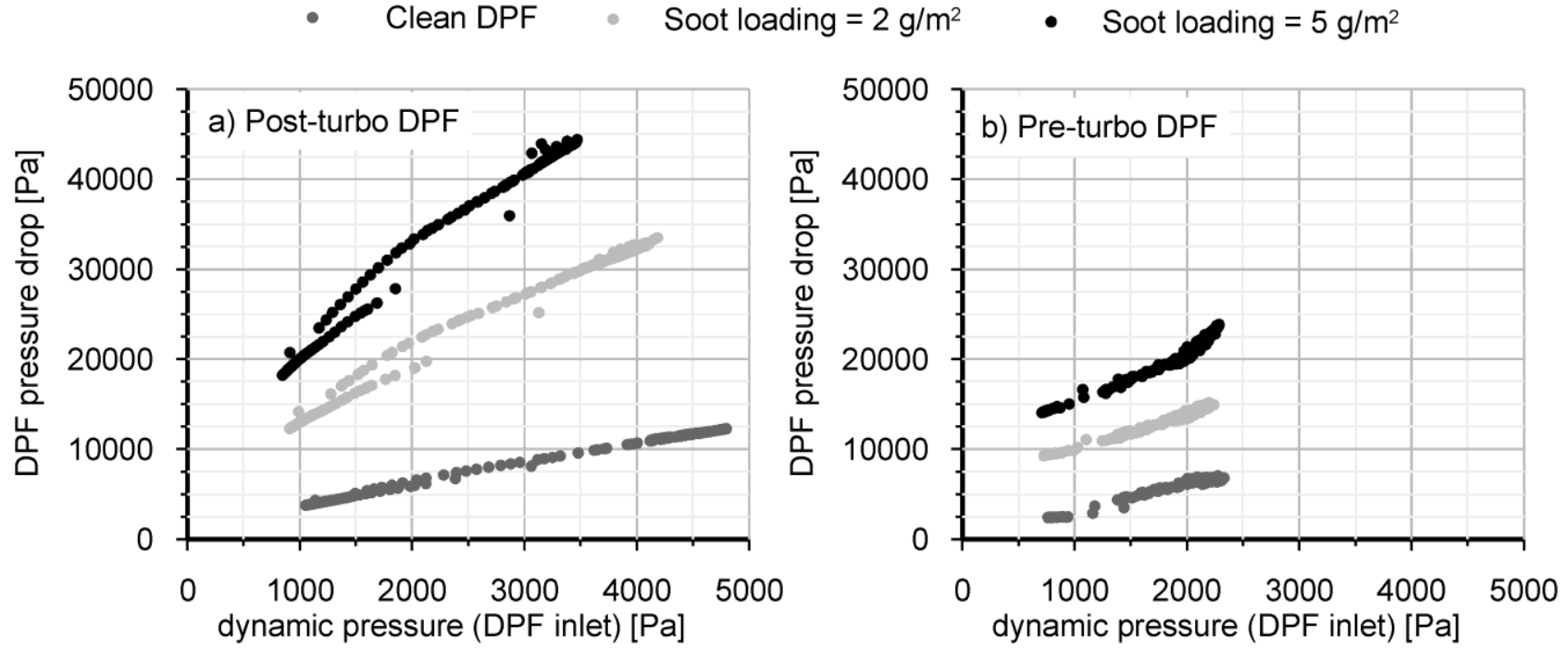

Figure 35.- Modelling of the pressure drop across the DPF under full-load transient operation at $2500 \mathrm{rpm}$ as function of the DPF placement and the soot loading conditions of the DPF.

Page 46 of 49 

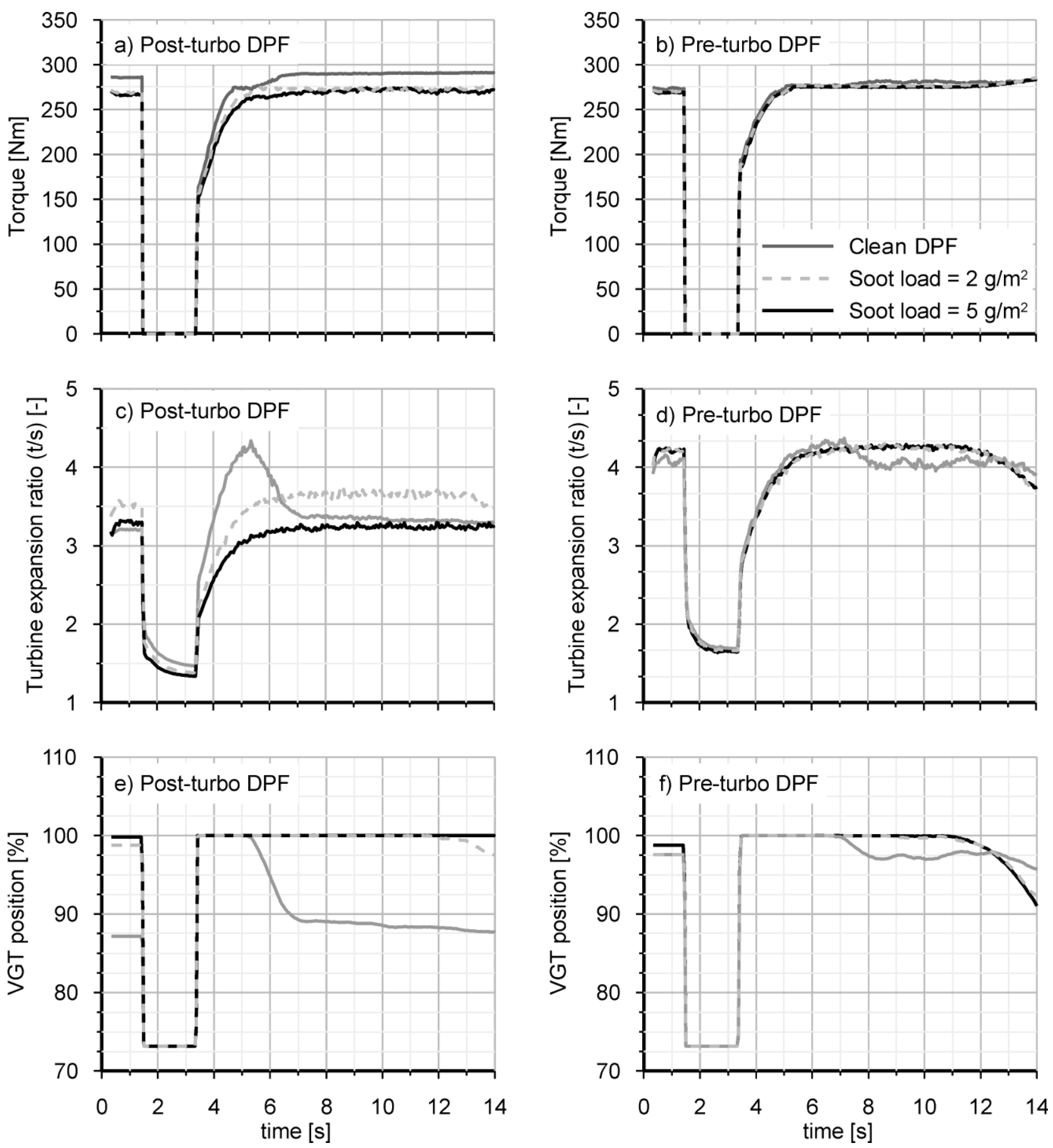

Figure 36.- Modelling of the dependence of the engine performance and the turbine expansion ratio under full-load transient operation at $2500 \mathrm{rpm}$ as function of the DPF placement and the soot loading conditions of the DPF.

Page 47 of 49 

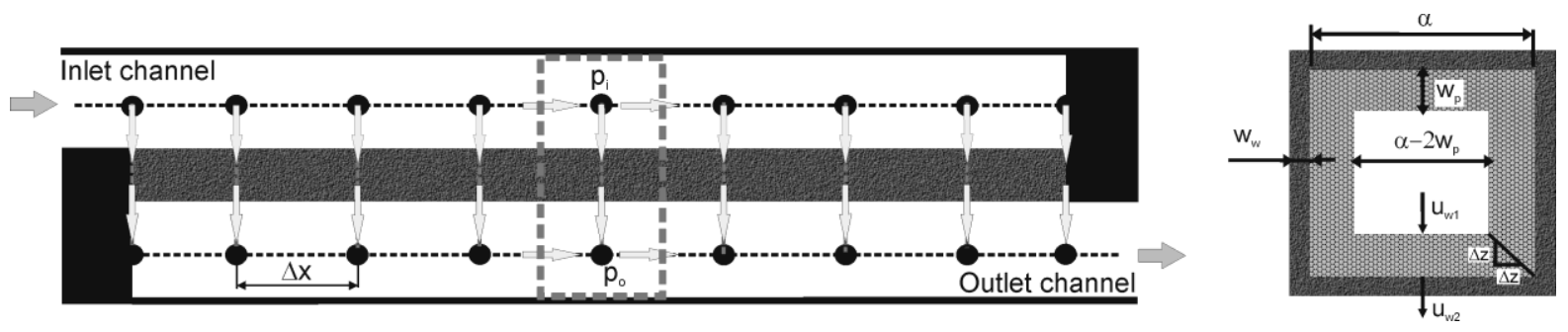

Figure 37.- Axial and cross-section geometry of channels in wall-flow DPF monoliths.

Page 48 of 49 
a) Nodal scheme in the porous wall

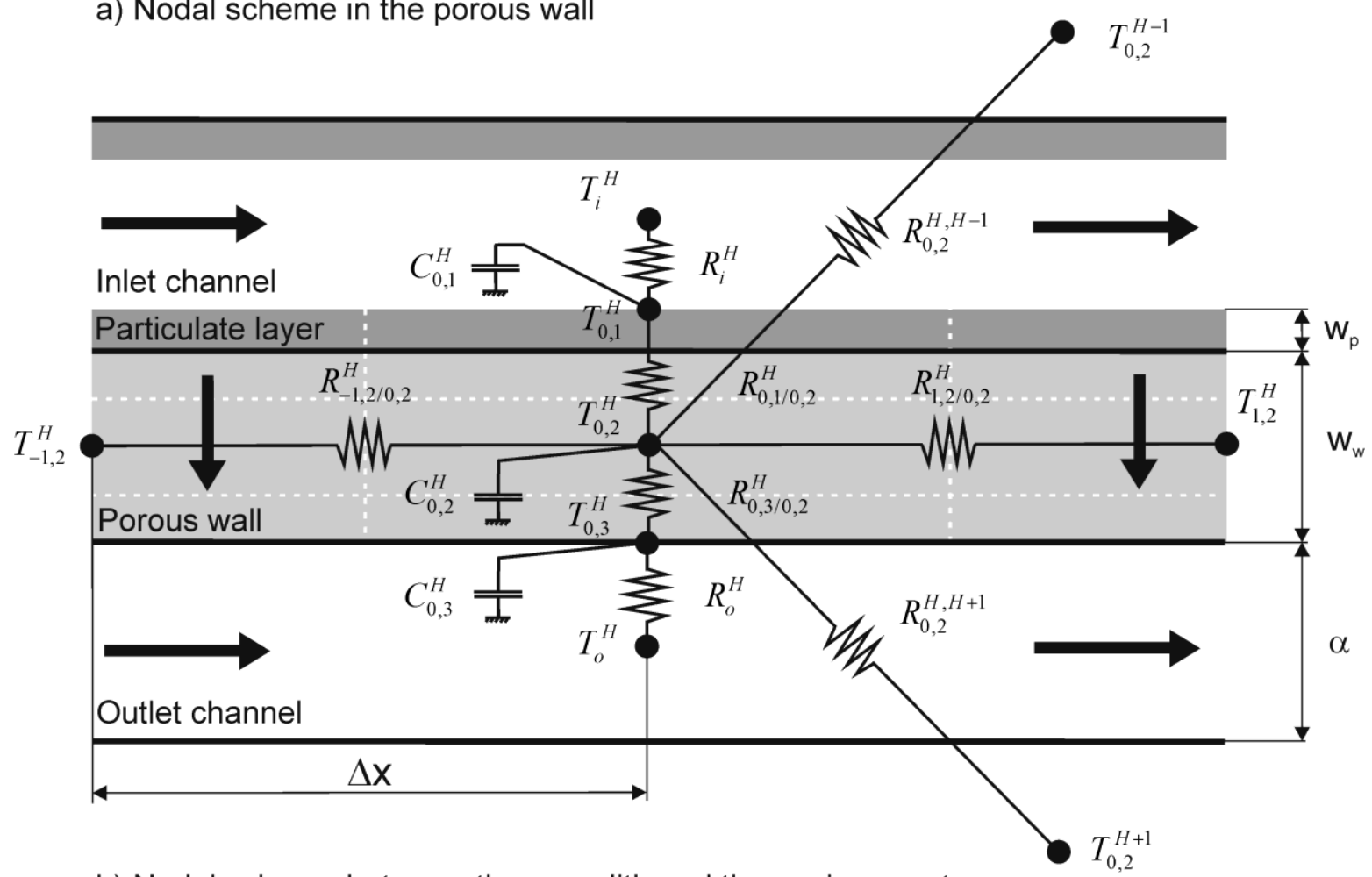

b) Nodal scheme between the monolith and the environment

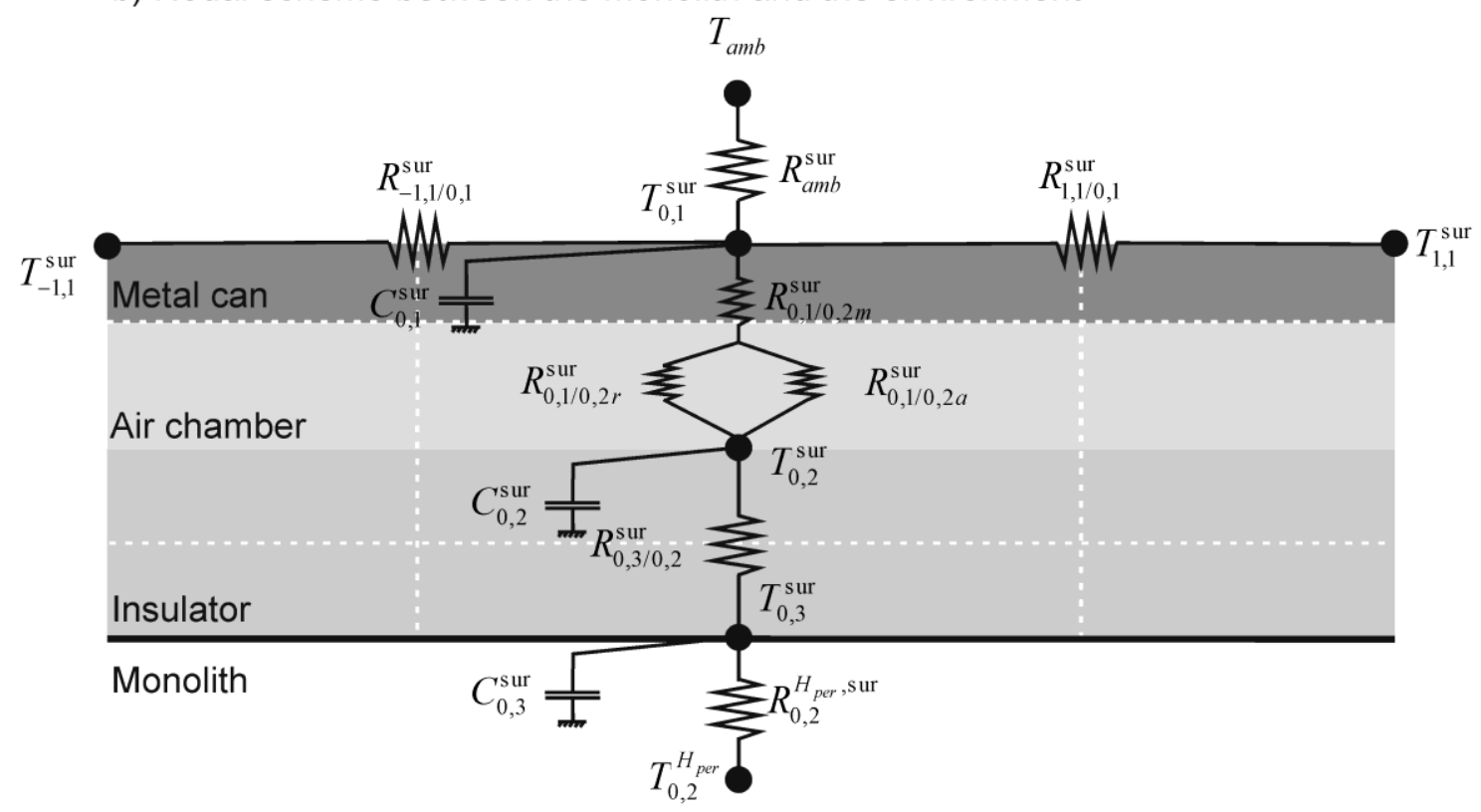

Figure 38.- Nodal schemes of the DPF heat transfer model: (a) in the porous wall, (b) in the canister of the monolith. 